\title{
Structure and characteristics of submonthly-scale waves along the Indian Ocean ITCZ
}

\author{
Yoshiki Fukutomi · Tetsuzo Yasunari
}

Received: 21 January 2012/ Accepted: 4 June 2012/Published online: 23 June 2012

(C) The Author(s) 2012. This article is published with open access at Springerlink.com

\begin{abstract}
This study examines wave disturbances on submonthly (6-30-day) timescales over the tropical Indian Ocean during Southern Hemisphere summer using Japanese Reanalysis (JRA25-JCDAS) products and National Oceanic and Atmospheric Administration outgoing longwave radiation data. The analysis period is DecemberFebruary for the 29 years from 1979/1980 through 2007/2008. An extended empirical orthogonal function (EEOF) analysis of daily $850-\mathrm{hPa}$ meridional wind anomalies reveals a well-organized wave-train pattern as a dominant mode of variability over the tropical Indian Ocean. Daily lagged composite analyses for various atmospheric variables based on the EEOF result show the structure and evolution of a wave train consisting of meridionally elongated troughs and ridges along the Indian Ocean Intertropical Convergence Zone (ITCZ). The wave train is oriented in a northeast-southwest direction from Sumatra toward Madagascar. The waves have zonal wavelengths of about $3,000-5,000 \mathrm{~km}$ and exhibit westward and southwestward phase propagation. Individual troughs and ridges as part of the wave train sequentially travel westward and southwestward from the west of Sumatra into Madagascar. Meanwhile, eastward and northeastward amplification of the wave train occurs associated with the successive growth of new troughs and
\end{abstract}

\footnotetext{
Y. Fukutomi $(\square)$

Research Institute for Global Change, JAMSTEC,

3173-25 Showamachi, Kanazawaku, Yokohama,

Kanagawa 236-001, Japan

e-mail: fukutomi@jamstec.go.jp

T. Yasunari

Hydrospheric Atmospheric Research Center, Nagoya University,

Furocho, Chikusaku, Nagoya, Aichi 464-8601, Japan

e-mail: yasunari@hyarc.nagoya-u.ac.jp
}

ridges over the equatorial eastern Indian Ocean. This could be induced by eastward and northeastward wave energy dispersion from the southwestern to eastern Indian Ocean along the mean monsoon westerly flow. In addition, the waves modulate the ITCZ convection. Correlation statistics show the average behavior of the wave disturbances over the tropical Indian Ocean. These statistics and other diagnostic measures are used to characterize the waves obtained from the composite analysis. The waves appear to be connected to the monsoon westerly flow. The waves tend to propagate through a band of the large meridional gradient of absolute vorticity produced by the mean monsoon westerly flow. This suggests that the monsoon westerly flow provides favorable background conditions for the propagation and maintenance of the waves and acts as a waveguide over the tropical Indian Ocean. The horizontal structure of the wave train may be interpreted as that of a mixture of equatorial Rossby waves and mixed Rossbygravity wavelike gyres.

Keywords Intertropical convergence zone - Indian ocean · Tropical wave disturbances $\cdot$ Submonthly-scale variability

\section{Introduction}

The Intertropical Convergence Zone (ITCZ) over the Indian Ocean is accompanied by deep and strong convection and is recognized as an important driving force of the global atmospheric circulation induced by the east-west Walker and local Hadley circulations. Statistical studies have revealed that the Indian Ocean ITCZ, like the Atlantic and Pacific ITCZs, is dominated by variability on various intraseasonal timescales associated with tropical convective disturbances (Vincent et al. 1998; Schrage et al. 2001; 
Roundy and Frank 2004). Since around the time of the Indian Ocean Experiment (INDOEX) field campaign in 1999 (Ramanathan et al. 2001), concern has been growing regarding the wind and convective disturbances associated with the transient behavior of the Indian Ocean ITCZ, given that these disturbances may transport aerosols from the Asian continent into the oceanic ITCZ region. The roles of various types of disturbances in determining the transport pathways and distributions of aerosols have been discussed (Krishnamurti et al. 1997; Lelieveld et al. 2001; Verver et al. 2001; de Laat and Lelieveld 2002; Krishnamurti et al 2009). The Madden-Julian Oscillation (MJO) is considered to play an important role in convective variability along the Indian Ocean ITCZ, as discussed by de Laat and Lelieveld (2002). Numerous studies on the MJO have demonstrated that active and suppressed phases of the MJO are associated with low-frequency intraseasonal alternation of strong and weak convection in the entire Indian Ocean ITCZ. In contrast, the existence of daily fluctuations with smaller scales governed by higher frequency disturbances has also been reported in the Indian Ocean ITCZ (Krishnamurti et al. 1997; Vincent et al. 1998; Schrage et al. 2001). Krishnamurti et al. (1997) and Schrage et al. (2001) found westward-propagating disturbances on synoptic timescales (4-6 and 2-3 days, respectively). Vincent et al. (1998) emphasized the importance of disturbances on submonthly (generally within the range of about 6-30 days) timescales for modulation of the ITCZ convection in the Indian Ocean-Pacific region. They found that convective activity on 6-25-day timescales extends all the way across the Indian Ocean ITCZ, especially in boreal winter. Their comprehensive review also documents that tropical submonthly-scale disturbances tend to correspond to equatorial Rossby-type waves linked to the ITCZ convection (e.g., Numaguti 1995; Kiladis and Wheeler 1995; Kiladis and Weickmann 1997; Pires et al. 1997; Wheeler and Kiladis 1999). Moreover, the submonthly-scale disturbances are responsible for tropical-extratropical interaction through dynamical response to convective forcing in the ITCZ (e.g., Kiladis and Weickmann 1992, 1994, 1997; Meehl et al. 1996). Submonthly-scale disturbances have been intensively investigated over the past two decades. However, most of these past works mainly considered the variability in the Pacific region. Although several studies partly documented the submonthly-scale disturbances associated with transient convective activity in the Indian Ocean region, less attention has been given to the detailed structure and behavior of the disturbances.

Recently, a growing number of studies have focused on dynamic and thermodynamic impacts of submonthly atmospheric wind fluctuations on the tropical Indian Ocean variability (e.g., Sengupta et al. 2001, 2004; Masumoto et al. 2005; Shinoda and Han 2005; Han et al. 2006, 2007;
Masumoto et al. 2008; Ogata et al. 2008; Duncan et al. 2009). While several of these studies have described the detailed structure and seasonality of the ocean circulation and thermodynamic conditions associated with the mixed Rossby-gravity waves forced by the atmospheric submonthly variability, structural and dynamical aspects of the atmospheric submonthly-scale disturbances themselves in this region have been relatively less investigated.

Most previous works on atmospheric submonthly-scale disturbances in the tropical Indian Ocean region have examined disturbances associated with the South Asian summer monsoon. For example, Chatterjee and Goswami (2004) and Yokoi and Satomura (2006) documented dynamic aspects of the disturbances as equatorial Rossby waves with a north-south double-gyre structure. On the other hand, Fukutomi and Yasunari (2005, 2009; hereafter FY05 and FY09) highlighted extratropical forcing of the equatorial convective disturbances. Compared with the research on disturbances in boreal summer, relatively few studies have examined other seasons. Specifically, Shinoda and Han (2005) and Wen et al. (2010) illustrated features of lower tropospheric disturbances in boreal autumn and spring, respectively. However, little work has been done on the disturbances in boreal winter.

Among oceanic ITCZs, the Indian Ocean ITCZ is the most active in boreal winter, having a well-developed band structure (e.g., Waliser and Gautier 1993; Tomas and Webster 1997). Nevertheless, the higher-frequency intraseasonal disturbance that perturbs this ITCZ has been comparatively less addressed. As shown by Vincent et al. (1998), submonthly-range convective signals are aligned with the Indian Ocean ITCZ and these signals are stronger than the MJO-range convective signals, suggesting that the disturbances on submonthly timescales could be primary modulators of the convective activity in the Indian Ocean ITCZ. Although a few previous climate studies on southern Africa noticed the existence of the submonthly-scale convective wave disturbances associated with the southwestern portion of the Indian Ocean ITCZ (Jury and Pathack 1991; Jury et al. 1991; Nassor and Jury 1998), the structure and dynamics of the wave disturbances in the broad tropical Indian Ocean region during boreal winter have not been well clarified. To address this issue, this study investigates the spatiotemporal structure of the dominant mode of wave disturbances on submonthly timescales over the tropical Indian Ocean

Specifically, we attempt to determine the structure and characteristics of the submonthly wave disturbances over the tropical Indian Ocean during Southern Hemisphere (SH) summer (boreal winter). We examine not only the basic structure and behavior of the disturbances, but also how these disturbances differ from those in other seasons. Dominant modes of submonthly variability are detected by 
performing an extended empirical orthogonal function (EEOF) analysis on the $850-\mathrm{hPa}$ meridional wind anomalies. Composite analyses based on the EEOF analysis result reveal the spatiotemporal structure and evolution of the wave train extending across the tropical Indian Ocean. Correlation statistics indicate the average behavior of the wave disturbances. The roles of the background mean flow in the development and maintenance of the wave train are discussed. Data for 29 boreal winters (December-February) from $1979 / 1980$ to $2007 / 2008$ are analyzed.

The remainder of this paper is organized as follows. Section 2 provides a brief description of the data and analysis procedure. Section 3 presents the climatology of disturbance activity in the Indian Ocean region. Section 4 highlights the composite spatial and temporal structure of the tropical wave disturbances. Section 5 describes the characteristics of the wave disturbances derived from correlation statistics. Section 6 analyzes a case of tropical wave development. Finally, we summarize and discuss our study in Sect. 7 .

\section{Data sets and analysis methods}

The primary data used for this study are extracted from global atmospheric reanalysis data sets provided by the Japan Meteorological Agency (JMA). The reanalysis data sets are the Japanese 25-year Reanalysis (JRA25) and its extended version, the JMA Climate Data Assimilation System (JCDAS) products, which cover the period from 1979 to the present. These data sets have been produced by the JMA numerical assimilation and forecast system and provide many kinds of assimilated and forecasted variables available at a 6-h temporal resolution and various grid types (Onogi et al. 2005, 2007). We used the atmospheric horizontal winds, geopotential height, temperature, and specific humidity on horizontal $2.5^{\circ}$ grids at 12 pressure levels $(100,150,200,250,300,400,500,600,700,850$, 925 , and 1,000 hPa) from the "anl-p25" subset of JRA25 (see Onogi et al. 2007). Following the method of FY05 and FY09, we computed stream function, velocity potential, divergence, and relative vorticity from horizontal winds using a spherical harmonic transform method. Vertical velocity was also computed from divergence. Daily averaged values of all the elements were used for data analysis. We also used daily outgoing longwave radiation (OLR) data to explore convective activities associated with tropical wave development. The OLR data were provided by the Earth System Research Laboratory (ESRL) of the United States National Oceanic and Atmospheric Administration (NOAA).

The data analysis was conducted for 29 boreal winters (December-February: DJF) from $1979 / 1980$ to $2007 / 2008$.
Anomaly time series of all the variables were computed by subtracting out the first three harmonics from the original 365-day time series to remove the seasonal cycle. The anomaly time series were then filtered into a 6-30-day band using the Butterworth band-pass filter of Kaylor (1977) to isolate submonthly components. This filter with half-power points at 6 and 30 days effectively reduces power in the range of higher-frequency synoptic-timescale fluctuations and lower-frequency intraseasonal variabilities such as the MJO. The anomaly data are subjected to various statistical analyses to capture tropical wave activities and wave structures. An EEOF analysis is conducted on the filtered $850-\mathrm{hPa}$ meridional wind to determine the main modes of tropical waves over the Indian Ocean. The resulting principal component (PC) time series is used as an index to construct lagged composite fields of the atmospheric variables. The composite fields are used to represent the structure and evolution of the tropical wave disturbances. Detailed descriptions of these analysis procedures are given in the later sections.

\section{Disturbance activities over the tropical Indian Ocean}

\subsection{Climatological mean and variance fields}

This section presents basic aspects of the mean climatological flow and submonthly-scale activities over the tropical Indian Ocean during the Asian winter monsoon. Figure 1a shows the winter-mean winds at $850 \mathrm{hPa}$ and the OLR. The northeasterly (NE) winter monsoon flow dominates areas north of the equator, especially the Arabian Sea and Bay of Bengal. The NE trade winds cross the equator; then, these winds turn eastward and merge into the monsoon westerlies south of the equator. On the other hand, southeasterly (SE) trade winds prevail over the southeastern Indian Ocean. These SE winds spread from the subtropical eastern Indian Ocean and converge at the monsoon westerly zone. The SE winds and the monsoon westerlies create a zonal wind shear line around $10^{\circ} \mathrm{S}$. The confluence of the cross-equatorial NE trades and the SE trades corresponds to the ITCZ as depicted by a band of lower OLR values extending from the north of Madagascar toward the Maritime Continent. The ITCZ couples well with the monsoon westerlies along the equatorial Indian Ocean $\left(10^{\circ} \mathrm{S}\right.$ to the equator).

A transient disturbance activity under the winter monsoon state is measured by variance computed from meridional wind at $850 \mathrm{hPa}$. Meridional wind can also be suitable for highlighting high-frequency disturbance activity over the Indian Ocean (e.g., Krishnamurti et al. 1997). Figure 1b shows the variance in daily unfiltered meridional wind anomalies. Three local maxima of 
Fig. 1 a Mean 850-hPa winds (vectors) and OLR (shadings) for DJF 1979/1980-2007/2008. b Total variance of unfiltered 850-hPa meridional wind anomalies (only annual cycle is subtracted). Contour interval is $1.0 \mathrm{~m}^{2} \mathrm{~s}^{-2}$. c Variance of 6-30day filtered $850-\mathrm{hPa}$ meridional wind anomalies (contours) and its percentage of the total variance (shadings). Contour interval is $1.0 \mathrm{~m}^{2} \mathrm{~s}^{-2}$. The key regions for the timeseries analysis is enclosed by the grid boxes of $5^{\circ} \mathrm{S}-5^{\circ} \mathrm{N}, 77.5^{\circ}-87.5^{\circ} \mathrm{E}$ and $10^{\circ} \mathrm{S}-20^{\circ} \mathrm{N}, 85^{\circ}-95^{\circ} \mathrm{E}$

d Teleconnectivity map of the 6-30-day filtered $850-\mathrm{hPa}$ meridional wind anomalies. Contour interval is 0.05 .

Contour starts at 0.35 (a) Mean $\quad$ 850hPa Wind \& OLR, DJF 1979/80-2007/08 10m/s

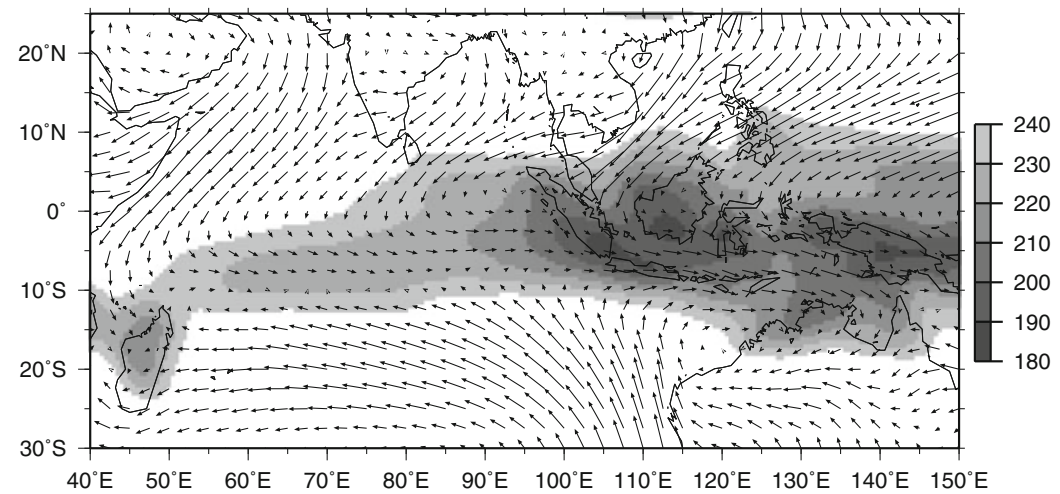

(b) Variance

DJF 1979/80-2007/08

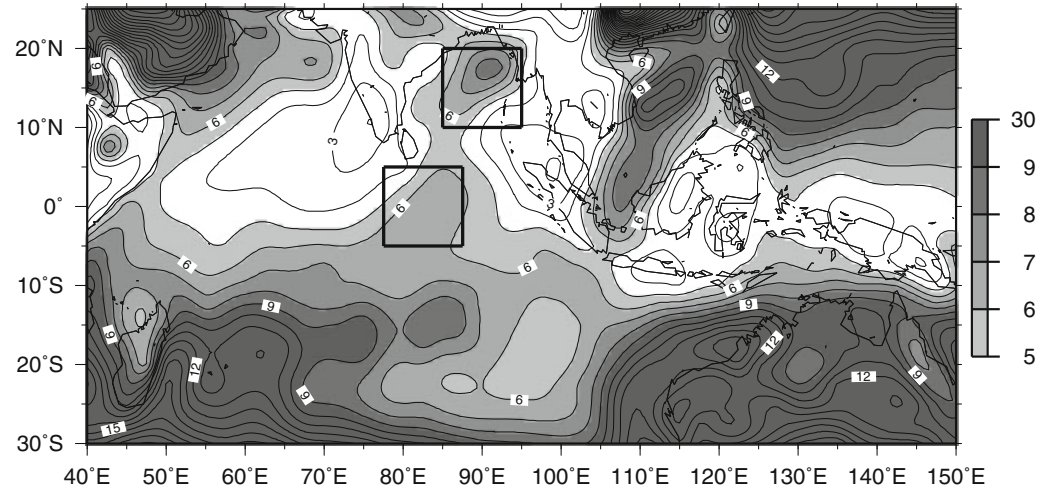

(c) Variance \& Ratio $\quad 850 \mathrm{hPa}$ V(6-30 days), DJF 1979/80-2007/08

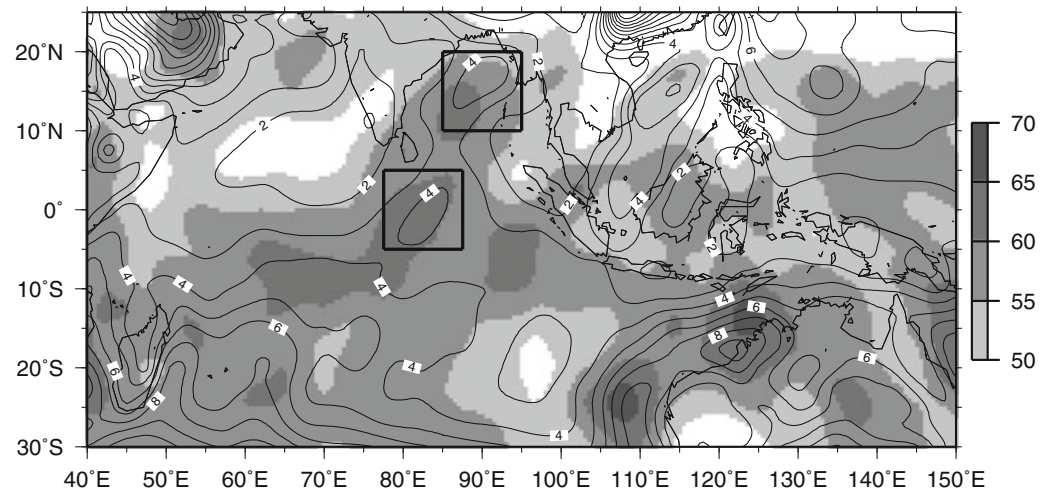

(d) Teleconnectivity $\quad$ 850hPa V(6-30 days), DJF 1979/80-2007/08

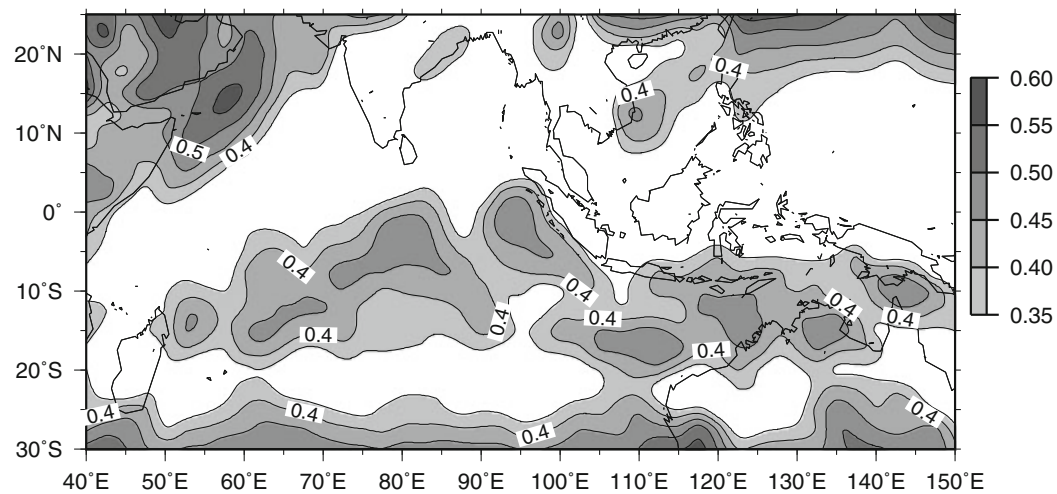


variance are found in the eastern Indian Ocean region. The equatorial variance maximum between $75^{\circ}$ and $90^{\circ} \mathrm{E}$ could characterize a variability of a transient cross-equatorial flow over the equatorial eastern Indian Ocean. The variance maximum over the Bay of Bengal can be associated with the activity of northerly winter monsoon surges, as illustrated by Verver et al. (2001). Another maximum can be seen centered at $60^{\circ} \mathrm{E}, 20^{\circ} \mathrm{S}$. This appears to be connected to the higher variability in the off-equatorial tropical Indian Ocean, which extends westward to the East African coast.

Figure 1c presents the variance of 6-30-day filtered meridional wind at $850 \mathrm{hPa}$ and the percentage of variance explained by this band. The percentage of variance is defined as the ratio of this band to the unfiltered (total subseasonal) variance (as in Fig. 1b). The pattern of the variance of the submonthly filtered meridional wind is basically similar to that of the unfiltered meridional wind. The local maxima of the variance over the equatorial eastern Indian Ocean and the Bay of Bengal almost coincide with a large percentage of variance (more than $65 \%$ ). A band of large values of the percentage of variance exceeding $65 \%$ can also be found along the SH-side equatorial Indian Ocean. These high-variance features are manifestations of the prominent submonthly-scale wave activity over the tropical Indian Ocean. Vincent et al. (1998) reported the climatological distributions of submonthly-scale convective variability over the tropical Indian Ocean and Pacific for all four standard seasons. They found a local maximum of OLR variance in the Indian Ocean ITCZ in DJF. This implies that this timescale is one of the dominant timescales of the Indian Ocean ITCZ variability. The band of the large percentage of variance of the submonthly-scale meridional wind (Fig. 1c) is well collocated with the band of the submonthly OLR variance (Fig. 5a of Vincent et al. 1998), suggesting that convectively coupled waves on submonthly scales exist along the Indian Ocean ITCZ.

Teleconnectivity (Wallace and Gutzler 1981) defined by simultaneous correlation statistics is also used as a measure of disturbance activity over the tropical Indian Ocean. Lau and Lau (1990) employed teleconnectivity to successfully illustrate the wavelike nature of tropical synoptic-scale disturbances. In the present work, the teleconnectivity associated with submonthly-scale disturbances is calculated from the 6-30-day filtered meridional wind time series at each grid point, in the same way as in the previously mentioned studies. A resulting teleconnectivity map is displayed in Fig. 1d. A zonally elongated band of strong teleconnectivity can be observed in the $0^{\circ}-20^{\circ} \mathrm{S}$ latitude belt, which extends southwestward from western Sumatra into northeastern Madagascar. Local maxima of strong teleconnectivity larger than 0.45 are aligned along the axis of the band, implying that the submonthly-scale disturbances have a strong wavelike character. At the same time, the band is located where both the Indian Ocean ITCZ and monsoon westerlies are pronounced, suggesting the presence of a tropical waveguide maintained with physical linkage to those background factors.

\subsection{Spectral properties}

Predominance of the submonthly-scale variability in the tropical Indian Ocean is confirmed by a power spectrum analysis. The power spectrum analysis based on a fast Fourier transform method is applied to time series of the unfiltered meridional wind averaged over two boxes (Fig. 1b and c) for the 29 winters. These boxes enclose regions of the local maximum variance and percentage variance over the equatorial eastern Indian Ocean $\left(5^{\circ} \mathrm{S}-\right.$ $\left.5^{\circ} \mathrm{N}, 77.5^{\circ}-87.5^{\circ} \mathrm{E}\right)$ and the Bay of Bengal $\left(10^{\circ}-20^{\circ} \mathrm{N}, 85^{\circ}-\right.$ $95^{\circ} \mathrm{E}$ ). For the calculation of power spectra, we basically follow the procedure used by FY05. A power spectrum is calculated for each 128-day (November 12-March 19) time series that each DJF period (90 days) is centered on. Before calculating a power spectrum, cosine-type tapering is performed on the first and last $10 \%$ of each 128-day time series. Figure 2 demonstrates the ensemble power spectra of the meridional wind for 29 winters at the above two locations. In both plots, significant powers are found in the submonthly range. These spectra capture the submonthly variability in the tropical Ocean region reasonably well.

\section{Spatial structure of wave disturbances}

\subsection{Extended EOF analysis}

To determine the dominant modes of submonthly-scale variability over the tropical Indian Ocean during northern winter, an EEOF analysis of the filtered 850-hPa meridional wind anomalies is performed over a domain enclosed by $20^{\circ} \mathrm{S}-20^{\circ} \mathrm{N}, 40^{\circ}-100^{\circ} \mathrm{E}$. EEOF modes are obtained by solving an eigenvalue problem of the lagged covariance matrix with two 1-day lags constructed from the time series for each winter at each grid point in the domain. The EEOF technique is suitable for extracting propagating wave modes in both the tropics (e.g., Lau and Lau 1992; Maloney 2003) and the extratropics (e.g., Vera et al. 2002).

The resulting first four EEOFs are displayed in Fig. 3. EEOFs 1, 2, 3, and 4 explain 8.6, 7.5, 7.0, and 5.2\% of the total variance, respectively. The first mode (EEOF 1) has maximum variance over the Arabian Sea. This mode could characterize the northerly monsoon surge activity originating from the Saudi Arabia-Pakistan region found by Murakami and Sumi (1981). The second and third modes (EEOFs 2 and 3) exhibit well-organized wave-train 

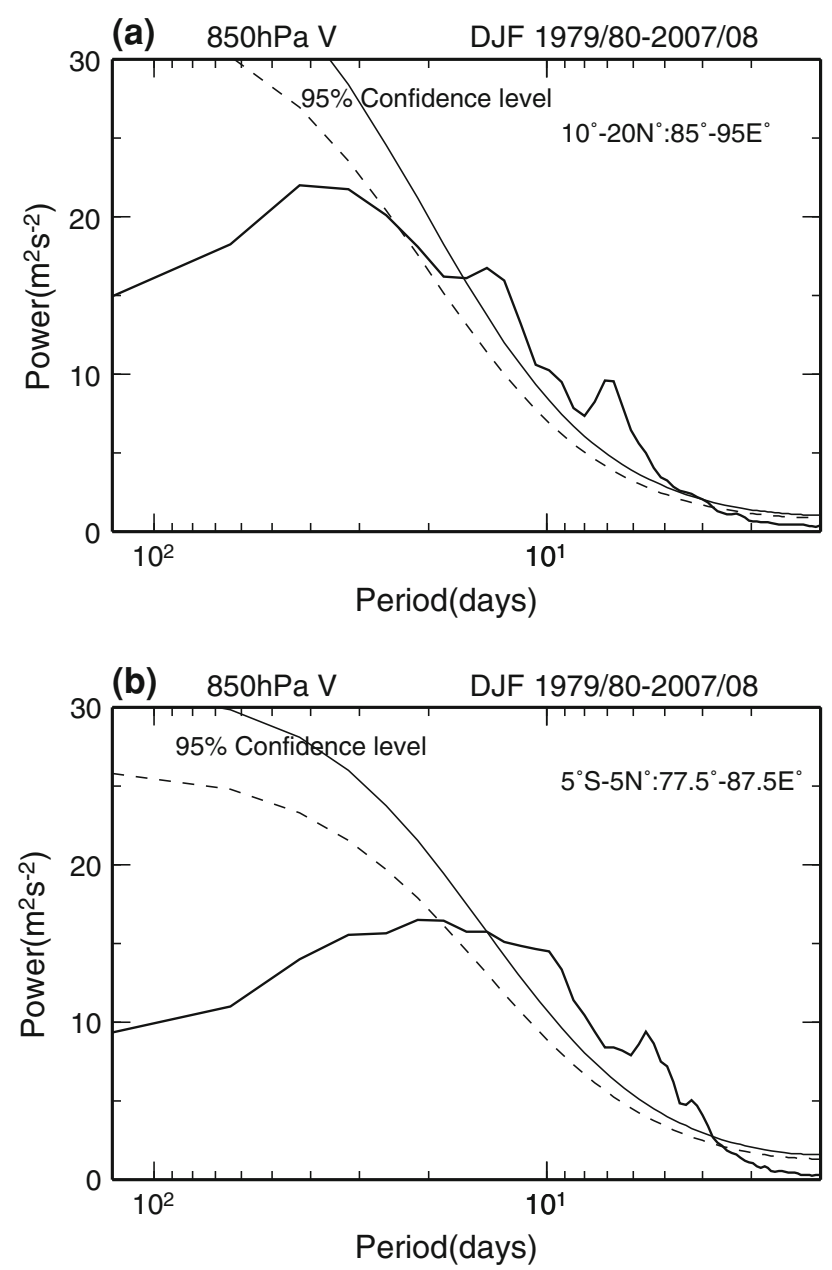

Fig. 2 a 29-SH summer ensemble power spectrum of $850-\mathrm{hPa}$ meridional wind averaged over the key region $\left(10^{\circ} \mathrm{S}-20^{\circ} \mathrm{N}, 85^{\circ}-\right.$ $\left.95^{\circ} \mathrm{E}\right)$. The thin solid curve represents the $95 \%$ confidence level. The dashed curve represents the red noise spectrum. (b) Same as a except for the key region $\left(5^{\circ} \mathrm{S}-5^{\circ} \mathrm{N}, 77.5^{\circ}-87.5^{\circ} \mathrm{E}\right)$

patterns over the tropical Indian Ocean. These patterns are similar and in quadrature with each other, suggesting that EEOFs 2 and 3 constitute a pair of modes that represent the same propagating wave. The wave trains are southwestnortheast-oriented and extend from Madagascar toward Sumatra Island. The fourth mode (EEOF 4) has a meridionally asymmetric structure in the eastern Indian Ocean region. This mode appears to be partly associated with the fluctuations in the northerly flow channels over the Bay of Bengal (e.g., Verber et al. 2001).

The two dominant modes of the low-level meridional wind disturbances are successfully detected as EEOFs 2 and 3 over the tropical Indian Ocean. As mentioned above, these two successive modes may reflect the same oscillation. Here, the relationship between the corresponding PCs (PCs 2 and 3) is also examined. The time series of these PCs have similar temporal structures, with PC 3 leading PC 2 by a few days (data not shown). The maximum

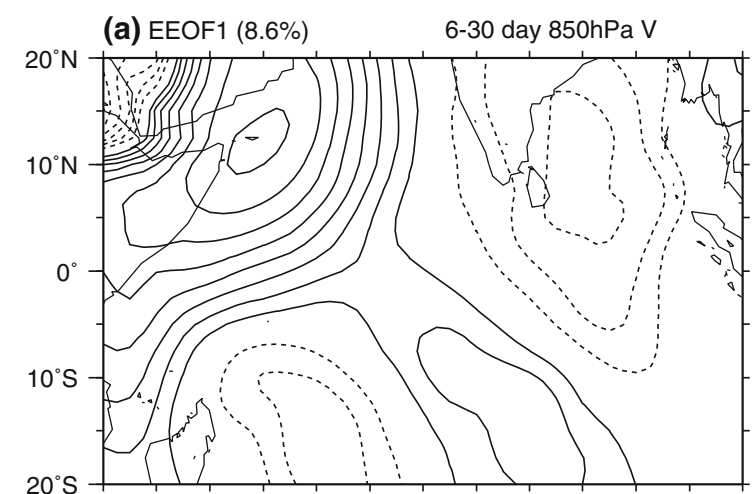

(b) EEOF2 (7.5\%) DJF 1979/80-2007/08

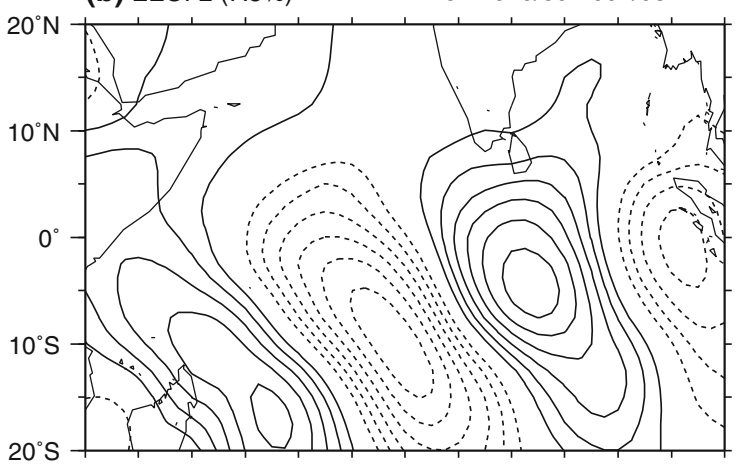

(c) EEOF3 (7.0\%)

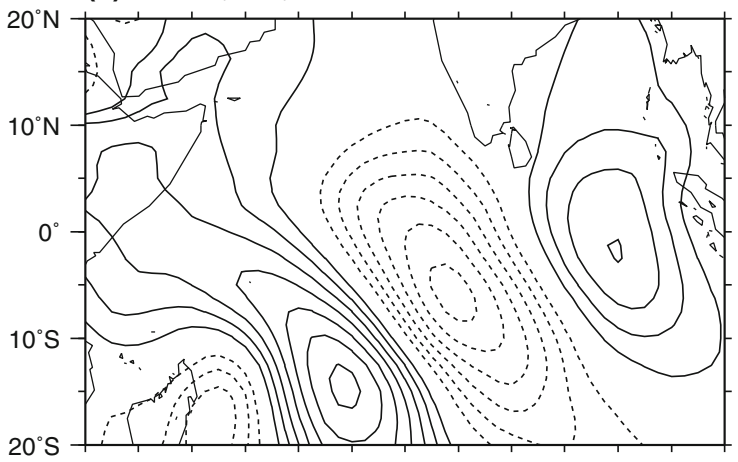

(d) EEOF4 (5.2\%)

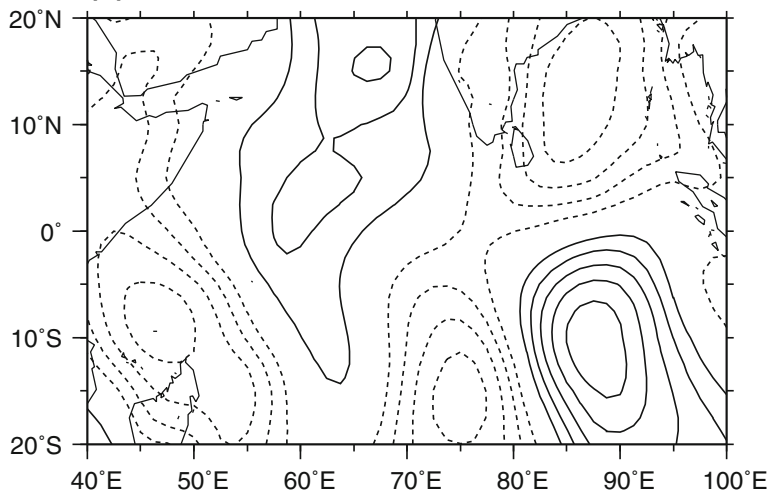

Fig. 3 Leading four EEOFs of 6-30-day filtered 850-hPa meridional wind anomalies. a EEOF1. b EEOF2. c EEOF3. d EEOF4. Contour interval is 0.1 (unit of correlation coefficient. Solid (dashed) contours indicate positive (negative) values 
correlation coefficient between them is 0.66 at a lag of 2 days. These results indicate that these two modes are a quadrature pair. This study targets the structure and evolution of the wave disturbances captured by these modes.

\subsection{Composite analysis}

We construct composites of various atmospheric variables based on the EEOF analysis result. For simplicity, we use the PC 2 time series as a single index to select temporal phases to create the composite fields. The EEOF 2 pattern is chosen because it appears to best represent the stage of maturely developed waves over the tropical Indian Ocean. We employ a standard deviation of 1.5 as the criterion for choosing positive and negative peaks of the index. As a result, 78 cycles of oscillation that include these peaks are identified. The chosen peaks are referred to as "day 0" phases. Daily lagged composite fields of the atmospheric variables are then constructed relative to the positive and negative peak (day 0) phases. In addition to the daily lagged composites, life-cycle composites are also created to capture the quasiperiodic oscillation nature of the mode. As in the study by Fukutomi and Yasunari (2002), an oscillation cycle is divided into eight phase categories. The positive (negative) peak phase of the oscillation is assigned as category 3 (7). The phase at which an increasing (decreasing) index curve crosses zero is assigned as category 1 (5). The remaining categories $2,4,6$, and 8 are intermediate phases.

\subsection{Horizontal structures}

Figure 4 displays composite maps of the 6-30-day filtered $850-\mathrm{hPa}$ meridional wind anomalies and wind vectors throughout the life cycle of the oscillation represented by EEOF 2. A wave-train structure extending from Sumatra to Madagascar can be clearly seen. The propagation path of this wave train is basically located on the high teleconnectivity band depicted in Fig. 1d. Troughs and ridges of the wave train are meridionally elongated and their axes are tilted in a northwest-southeast direction. The meridional extent of the troughs and ridges is large enough to cover the entire tropical Indian Ocean on the SH side. The systematic southwestward propagation of wave signals with zonal wavelengths of about $3,000-5,000 \mathrm{~km}$ is also evident. A clockwise (counterclockwise) circulation as part of the wave train develops over the equatorial eastern Indian ocean from categories 1 (5) through 3 (7). These circulation cells could be strongly connected to the variability of the northerly cross-equatorial flow over the eastern Indian Ocean under the winter monsoon condition (as in Fig. 1a). The clockwise (counterclockwise) circulation is initially centered near the equator west to Sumatra in category 2 (6). It then travels southwestward and arrives east of Madagascar after about one and half cycles of the oscillation [category 4 (8) in the next cycle]. The circulation finally decays over the Madagascar-southeast African coastal region.

Daily lagged composites of the 6-30-day filtered wind vectors, stream function at $850 \mathrm{hPa}$, and OLR anomalies from day -4 through day +2 are presented in Fig. 5. These are constructed based on the positive peaks of the index time series. In this case, the composites are assigned as "positive composites". Day 0 represents the timing of the peak of the index. A wave train with a southwest-northeast orientation has already established over the entire tropical Indian Ocean by day -4 . Anomalous troughs and ridges constituting the wave train exhibit northwest-southeast elongation as defined by the lifecycle composites (Fig. 4). The waves (troughs and ridges) propagate westward and southwestward from the equatorial eastern Indian Ocean into the southwestern Indian Ocean throughout the sequence. For example, a trough (a cyclonic circulation in the SH sense) centered on the equatorial eastern Indian Ocean on day -4 moves westward into the central-western Indian Ocean by day +2 . The trough continues to move westward and eventually decays to the north of Madagascar after day +4 (data not shown). Trough regions accompany significant negative OLR anomalies, suggesting that the waves have a characteristic of convectively coupled equatorial waves along the Indian Ocean ITCZ. Convective signals tend to develop well along anomalous northwesterly flows as the northeastern part of troughs (southwestern part of ridges) on the SH side. These flows could bring moist air into the interior of the troughs and help maintain the moist unstable condition. The convective signal in the southwestern Indian Ocean trough is maximally enhanced. Notably, a ridge [a cyclonic circulation in the Northern Hemisphere ( $\mathrm{NH}$ ) sense] over the equatorial eastern Indian Ocean locates the convective signal at its northern flank (on the $\mathrm{NH}$ side) from day 0 through day +2 .

Composites of vorticity anomalies allow us to capture sharper structures of the waves. Figure 6 illustrates the temporal evolution of $850-\mathrm{hPa}$ vorticity perturbations together with the wind vectors in a similar manner as in Fig. 5. The patterns show a clear, well-defined wave packet with westward and southwestward phase propagation from day -4 through day +2 as in Fig. 4 . Of particular interest is the successive growth of the gyres in the eastern part of the wave train. As troughs and ridges move westwardsouthwestward, they are amplified over the southwestern Indian Ocean. Then, new troughs and ridges grow over the equatorial central-eastern Indian Ocean from day -2 through day 0 , suggesting downstream (eastward) dispersion of the waves along the monsoon westerlies. Another 
(a) Category 1 6-30 day 850hPa V, DJF 1979/80-2007/08

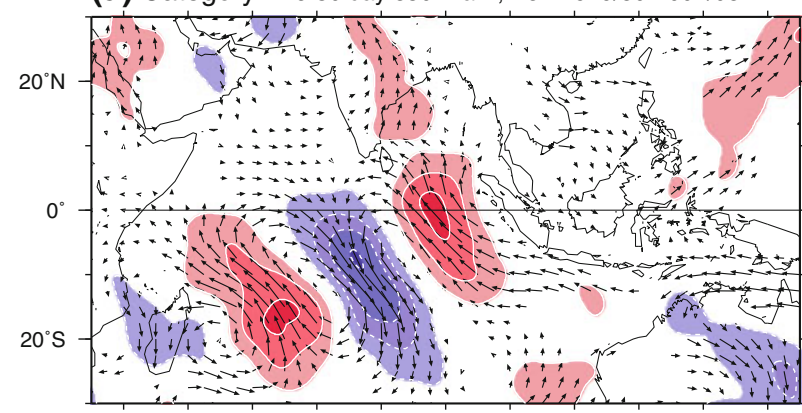

(b) Category 2

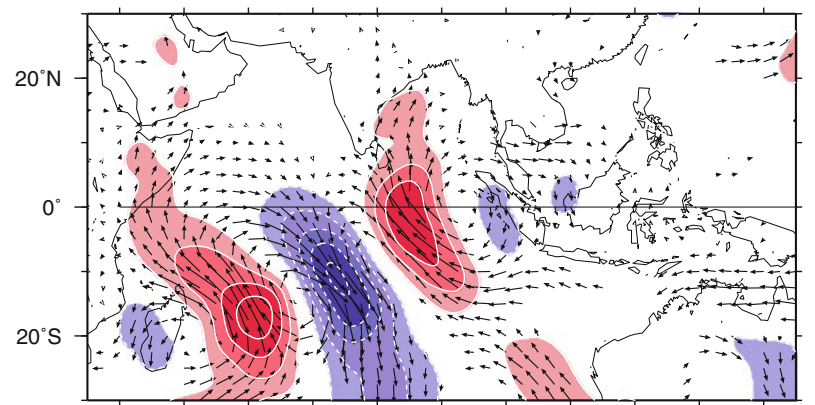

(c) Category 3

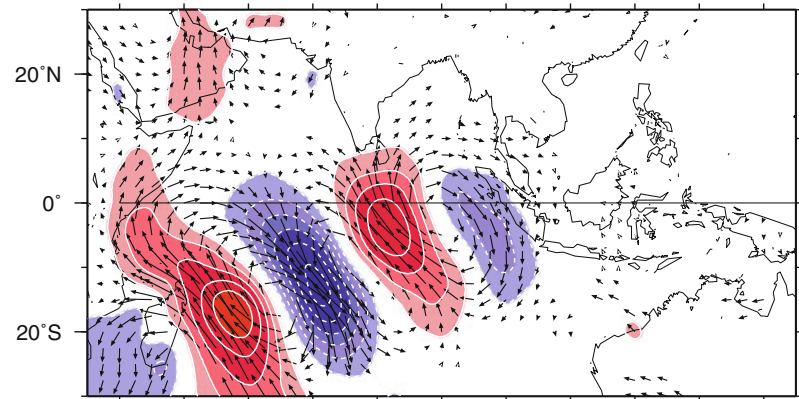

(d) Category 4

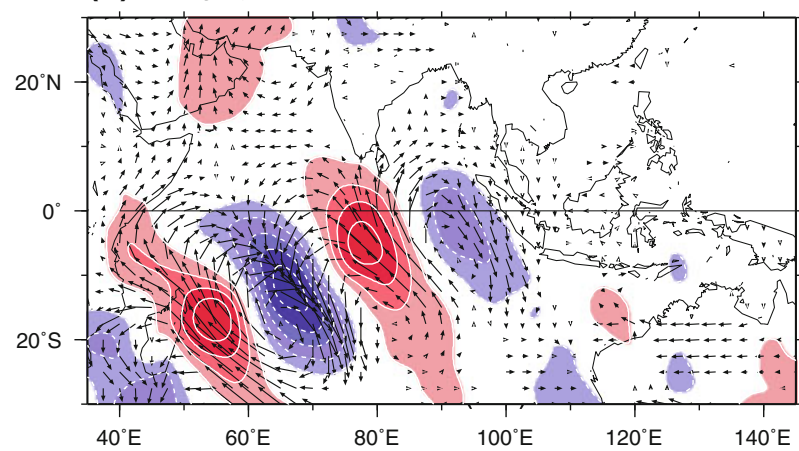

Fig. 4 Composite life cycle of 6-30-day filtered 850-hPa meridional wind anomalies (shades and contours) and wind vectors for phase category 1 through 8 based on the PC2 index. Red shades with solid

notable feature is observed in the decay stage of the waves. When the trough reaches Madagascar, its structure is somewhat deformed and has shrunk by day 0 . After passing

\section{2m/s (e) Category 5 6-30 day 850hPa V, DJF 1979/80-2007/08}

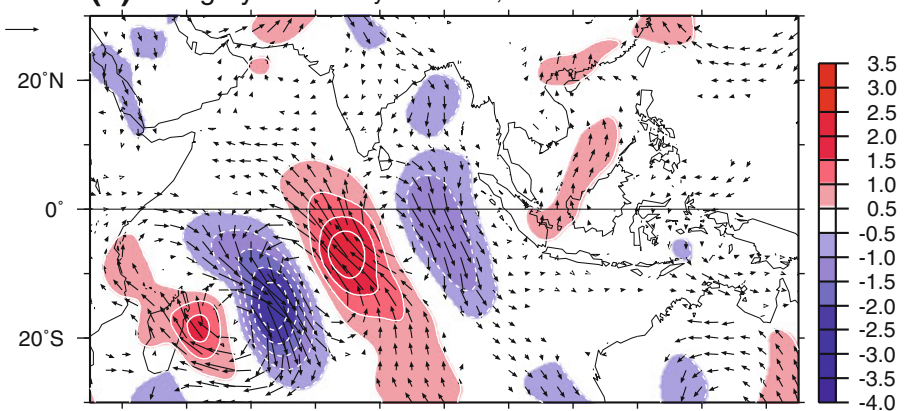

(f) Category 6

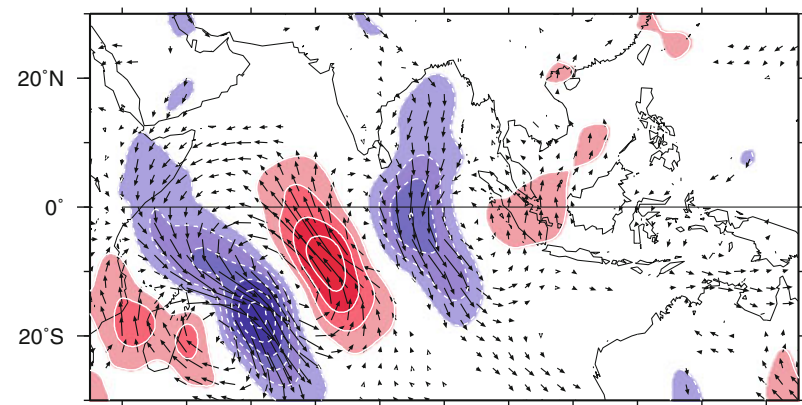

(g) Category 7

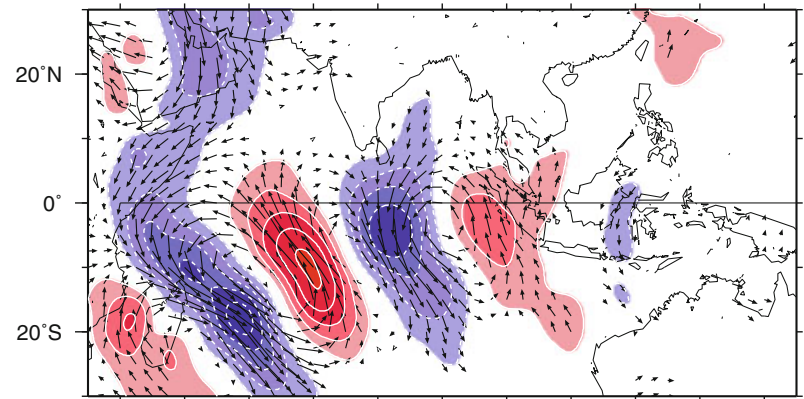

(h) Category 8

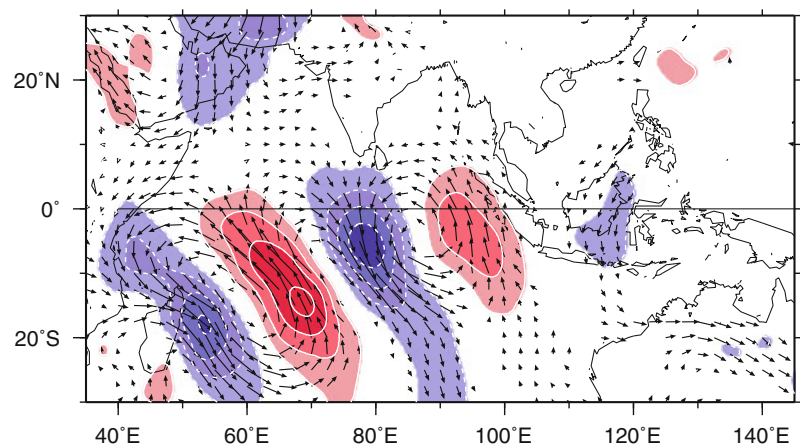

contours (blue shades with dashed contours) indicate positive (negative) values. 0 contours are omitted. Contour interval is $0.5 \mathrm{~m} \mathrm{~s}^{-1}$. Only $95 \%$ statistically significant vectors are plotted

through Madagascar, the trough rapidly dissipates to the southwest by day +2 . This suggests that the orographic effect of Madagascar plays a role in damping waves 
Fig. 5 Daily lagged composites of 6-30-day filtered $850-\mathrm{hPa}$ wind vectors, stream function, and OLR anomalies from day -4 through day +2 with 2-day interval based on the PC2 index. Positive (negative) stream function contours are solid (dashed). Contour interval is $2.0 \times 10^{5} \mathrm{~m}^{2} \mathrm{~s}^{-1}$. Negative (positive) OLR anomalies are shaded with blue (red) colors. Only $95 \%$ statistically significant vectors are plotted. OLR values with significant at the $95 \%$ level are enclosed by thick solid contours (a) Day $-4 \quad 6-30$ day $850 h P a$ Winds \& OLR (EEOF2) $2 \mathrm{~m} / \mathrm{s} \longrightarrow$

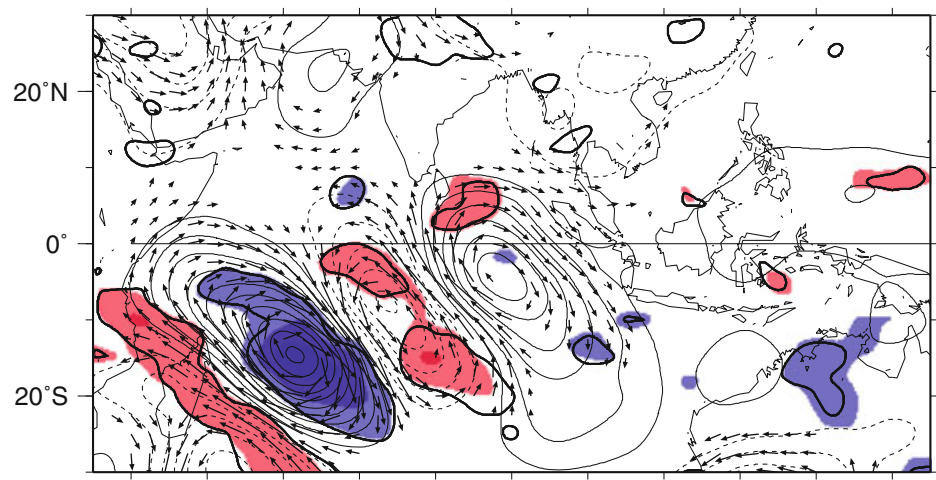

(b) Day -2

DJF 1979/80-2007/08

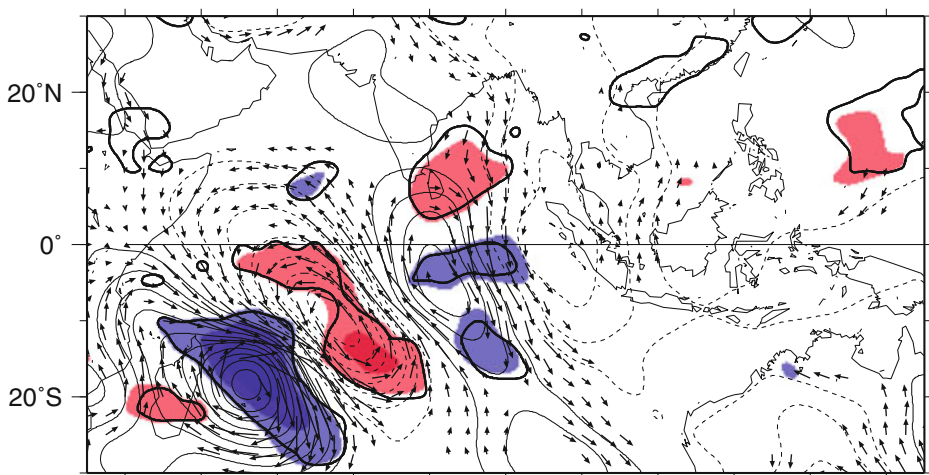

(c) Day -0

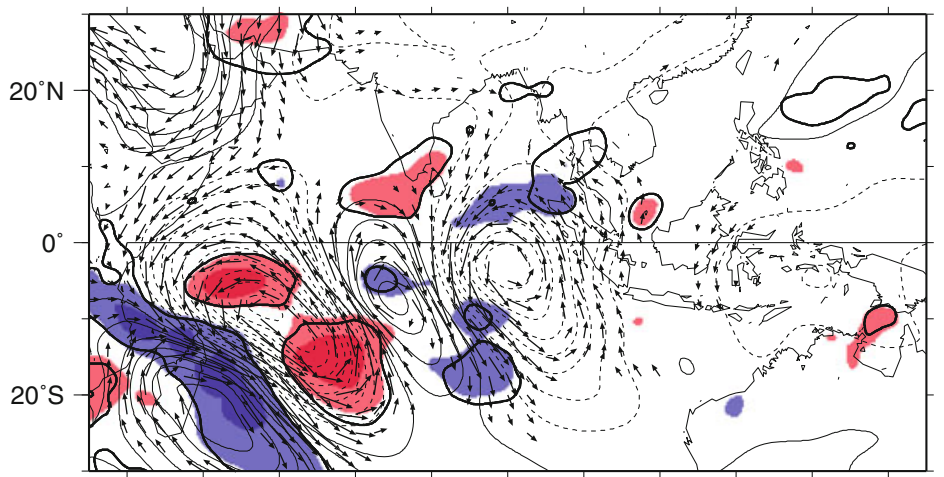

(d) Day +2

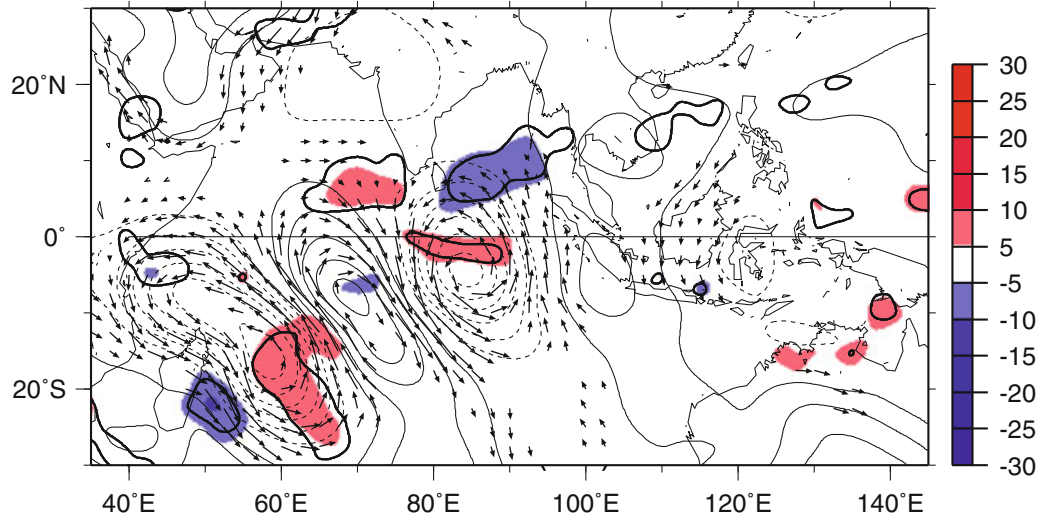


Fig. 6 Daily lagged composites of 6-30-day filtered wind vectors, and vorticity anomalies from day -4 through day +2 with 2-day interval based on the PC2 index. Red shades with solid contours (blue shades with dashed contours) indicate positive (negative) values.

Contour interval is

$0.2 \times 10^{-5} \mathrm{~s}^{-1}$. Only $95 \%$ statistically significant vectors are plotted. The thick line extending northeastward from $40^{\circ} \mathrm{E}, 25^{\circ} \mathrm{S}$ to $120^{\circ} \mathrm{E}, 15^{\circ} \mathrm{N}$ in c used for the vertical composites (Fig. 7)

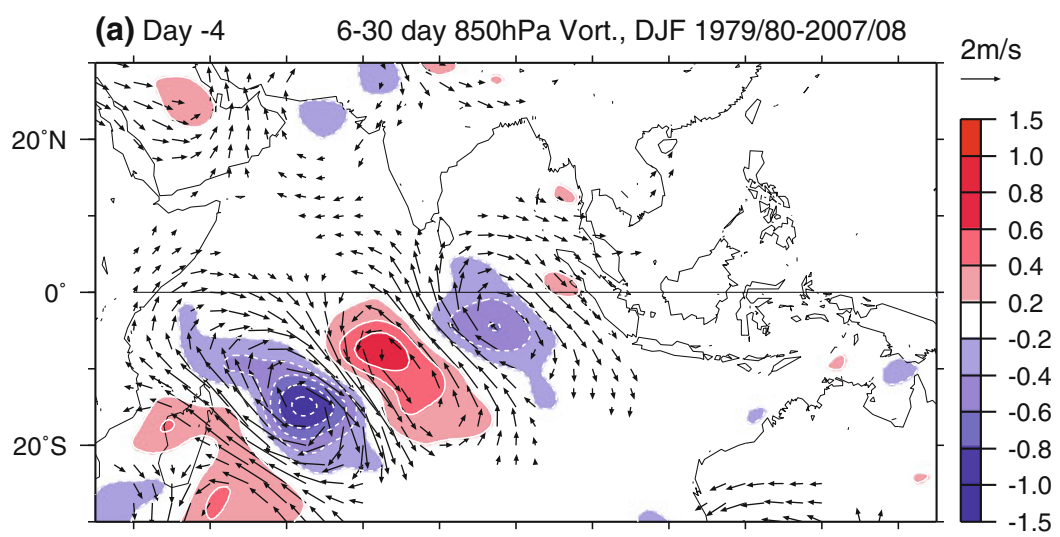

(b) Day -2

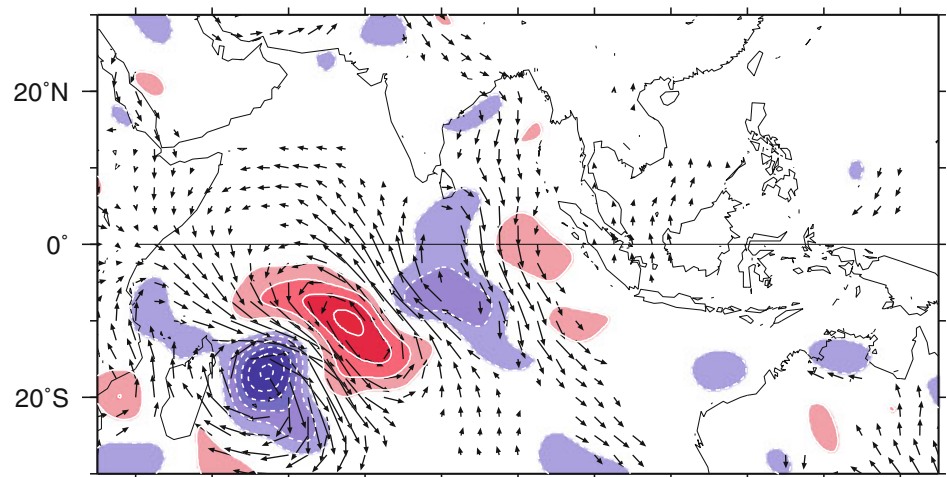

(c) Day 0

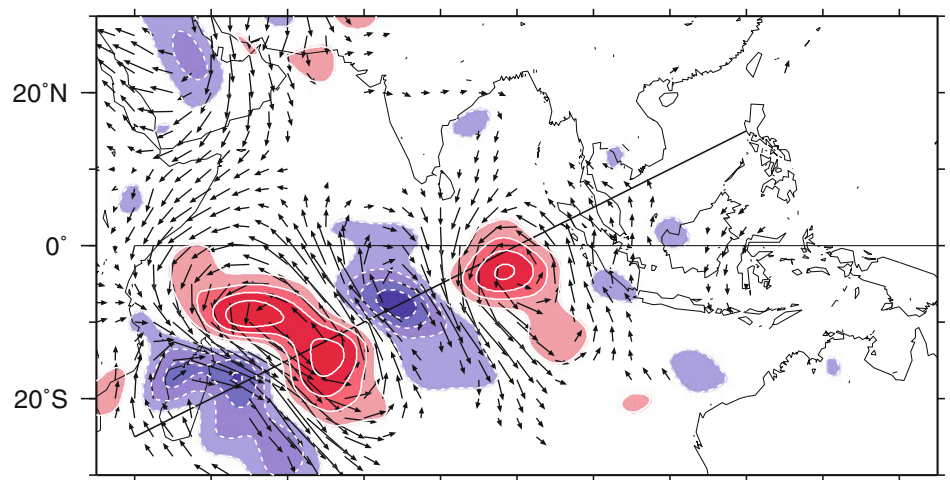

(d) Day 2

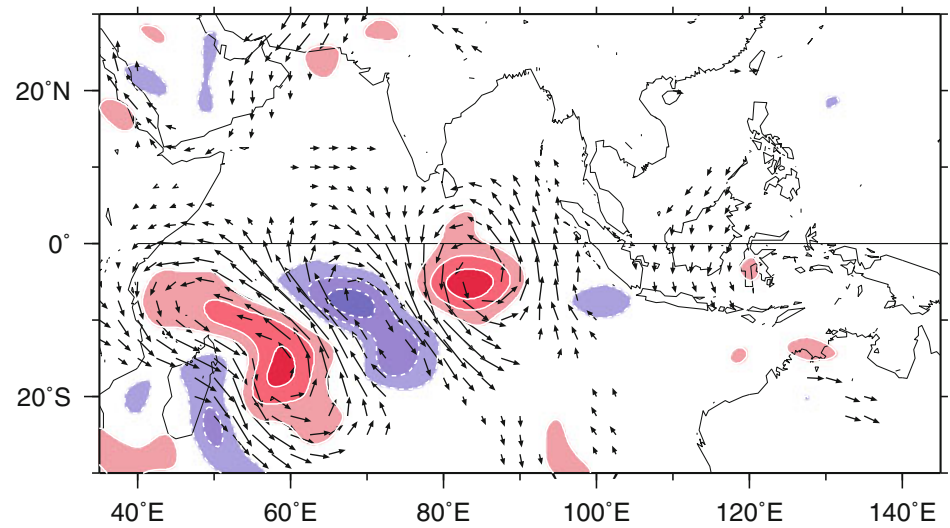


traveling from the northeast. We also examined anomalous vorticity composites based on the negative peaks of the index in the same way (data not shown). Similar, but out of phase, wave patterns to those in Fig. 5 were obtained from these "negative composites". Overall, the horizontal structures of the lower-tropospheric vorticity waves in both (positive and negative) composites identify rather clear westward and southwestward phase propagation and eastward and northeastward dispersion of the wave packet. A clockwise (or counterclockwise) gyre centered near the equator initially grows from the west of Sumatra and subsequently travels as part of the wave packet westward and southwestward into the southwestern Indian Ocean. In contrast, the wave packet successively develops eastward and northeastward into the eastern Indian Ocean.

\subsection{Vertical structures}

We also examine the vertical structures of the tropical waves, similar to the examination of the horizontal composites. Composite meridional wind, vorticity, vertical pressure velocity, and temperature anomalies at 12 pressure levels are obtained along a line extending from $40^{\circ} \mathrm{E}, 25^{\circ} \mathrm{S}$ to $120^{\circ} \mathrm{E}$, $15^{\circ} \mathrm{N}$. This line approximately corresponds to the propagation path of the waves observed in the horizontal composites.

Figure 7 shows vertical cross sections of the above elements at day 0 (positive peak phase). A well-developed train of deep northerlies and southerlies forms along the line, and meridional wind perturbations clearly reach maxima in the lower troposphere (Fig. 7a). The axes of the perturbation maxima are almost straight up to around $300 \mathrm{hPa}$ and tilted southwestward with height from 300 to $100 \mathrm{hPa}$. These features indicate that the perturbations exhibit an equivalent barotropic structure extending throughout the lower and mid-troposphere and a baroclinic structure in the upper troposphere. The vorticity perturbations also exhibit a deep barotropic structure in the lower and middle troposphere, and most of the maxima of the perturbations are confined to the lower troposphere below $500 \mathrm{hPa}$ (Fig. 7b). A negative perturbation to the west of about $58^{\circ} \mathrm{E}$ abruptly tilts from the $300-400 \mathrm{hPa}$ layer, and a large southwestward shift occurs up to roughly $100 \mathrm{hPa}$, indicating a strong baroclinic condition. Here, this perturbation is consistent with the cyclonic circulation coupling with deeper convection over the southwestern Indian Ocean (Fig. 4). This upper-level baroclinic structure can be produced by this convection in the cyclonic region. Vertical motion indicates stronger signals in the mid- to upper troposphere (Fig. 7c). Compared with the vorticity perturbations (Fig. 7b), upward and downward motion perturbations are associated with cyclonic and anticyclonic perturbations, respectively. Over the central and eastern Indian Ocean (about $65^{\circ}-85^{\circ} \mathrm{E}$ ), upward (downward) motion is located to the east of the cyclonic (anticyclonic) vorticity perturbations with a quadrature phase lag. In contrast, stronger upward motion throughout the troposphere over $50^{\circ}-60^{\circ} \mathrm{E}$ is almost in phase with the cyclonic perturbation. Higher temperature variations concentrate over the southwestern Indian Ocean (Fig. 7d). An upperlevel warming maximum centered at about $300 \mathrm{hPa}$ is presumably caused by convective heating. Another warm perturbation occurs in the lower troposphere over the same horizontal location. This warming signal may be due to advection of heat in the cyclonic region.

The vertical structures of the wave disturbances identified in this study are somewhat different from those of tropical synoptic-scale waves observed in the western Pacific region (e.g., Lau and Lau 1990; Maloney and Dickinson). The tropical synoptic-scale waves in this region exhibit a vertical phase tilt of the trough and ridge axes originating from the lower troposphere. However, the submonthly-scale waves over the tropical Indian Ocean do not indicate a strong vertical phase tilt in the lower troposphere along the propagation path. It is worth noting that Serra et al. (2008) also found a partly non-tilted structure of the synoptic-scale waves over the western Pacific.

\section{Wave propagation characteristics}

In this section, we investigate the characteristics of the waves propagating over the tropical Indian Ocean. According to the low-level horizontal composites in Figs. 4, 5 and 6, clear westward and southwestward phase propagation of the circulation anomalies takes place over the tropical Indian Ocean. At the same time, eastward and northeastward wave energy dispersion appears to occur. The phase and group speeds of the wave train are estimated from a longitude-time diagram of $850-\mathrm{hPa}$ meridional wind and vorticity anomalies. Figure 8 depicts $850-\mathrm{hPa}$ meridional wind anomalies from day -7 through day +7 along the latitude band of $20^{\circ} \mathrm{S}-0^{\circ}$. This longitude-time diagram is based on the positive composites. An average phase speed of $-4.5 \mathrm{~m} \mathrm{~s}^{-1}$ is estimated from a phasespeed line drawn along the negative anomalies showing westward phase propagation. The same line is almost applicable to other positive and negative anomalies. Another line in Fig. 8 corresponds to an average group speed of $8 \mathrm{~m} \mathrm{~s}^{-1}$. This line passes through near maxima of individual positive and negative anomalies, providing evidence of eastward energy dispersion of the waves. We also examined longitude-time diagrams for the negative composite case of meridional wind anomalies and positive and negative composite cases of vorticity anomalies (data not shown). Similar features were identified, and westward phase speeds and eastward group speeds were estimated to 
Fig. 7 Vertical cross-sections of a meridional anomalies, b vorticity anomalies, $\mathbf{c}$ vertical pressure velocity, $\mathbf{d}$ temperature anomalies on day 0 along the line extending from $40^{\circ} \mathrm{E}$, $25^{\circ} \mathrm{S}$ to $120^{\circ} \mathrm{E}, 15^{\circ} \mathrm{N}$ (Fig. 6c). Contour intervals for $\mathbf{a}-\mathbf{d}$ are a $0.25 \mathrm{~m} \mathrm{~s}^{-1}$, b $0.2 \times 10^{-5} \mathrm{~s}^{-1}$, c $0.005 \mathrm{~Pa} \mathrm{~s}^{-1}$, d $0.05 \mathrm{~K}$.

Solid(dashed) contours indicate positive (negative) values.

Positive (negative) anomalies with statistically significant at the $95 \%$ level are lightly (darkly) shaded (a) Day $0 \quad V\left(6-30\right.$ day) $\quad 40^{\circ} \mathrm{E}, 25^{\circ} \mathrm{S}-120^{\circ} \mathrm{E}, 15^{\circ} \mathrm{N}$

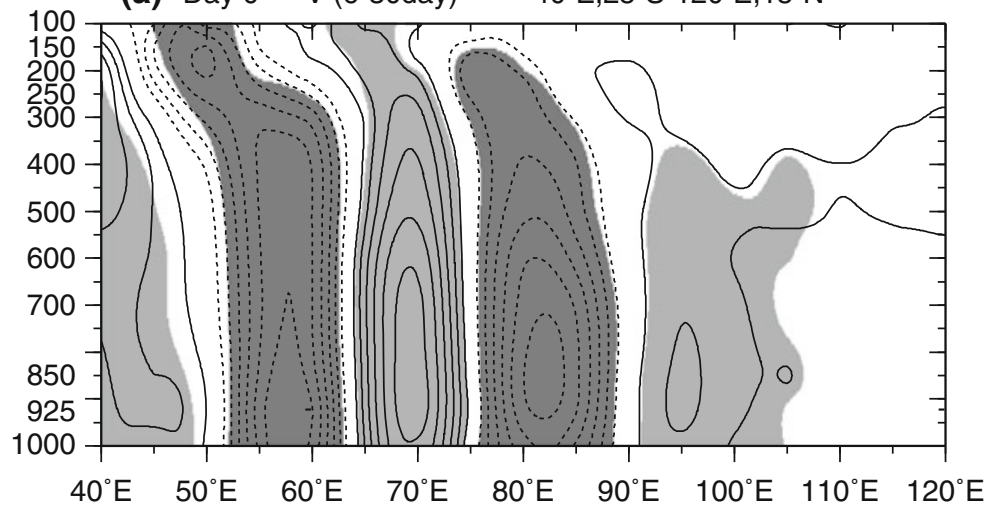

(b) Day 0 Vort. (6-30day) $40^{\circ} \mathrm{E}, 25^{\circ} \mathrm{S}-120^{\circ} \mathrm{E}, 15^{\circ} \mathrm{N}$

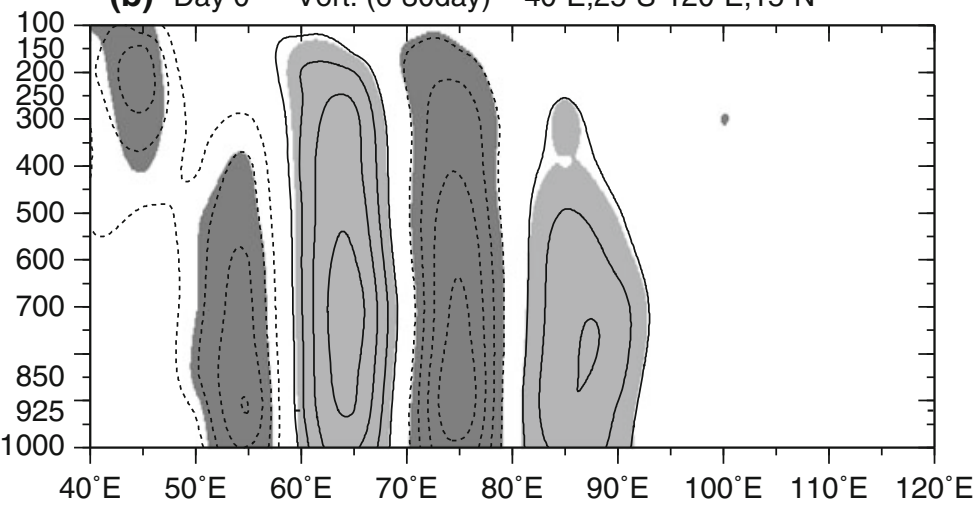

(c) Day 0 Omg. (6-30day) $40^{\circ} \mathrm{E}, 25^{\circ} \mathrm{S}-120^{\circ} \mathrm{E}, 15^{\circ} \mathrm{N}$

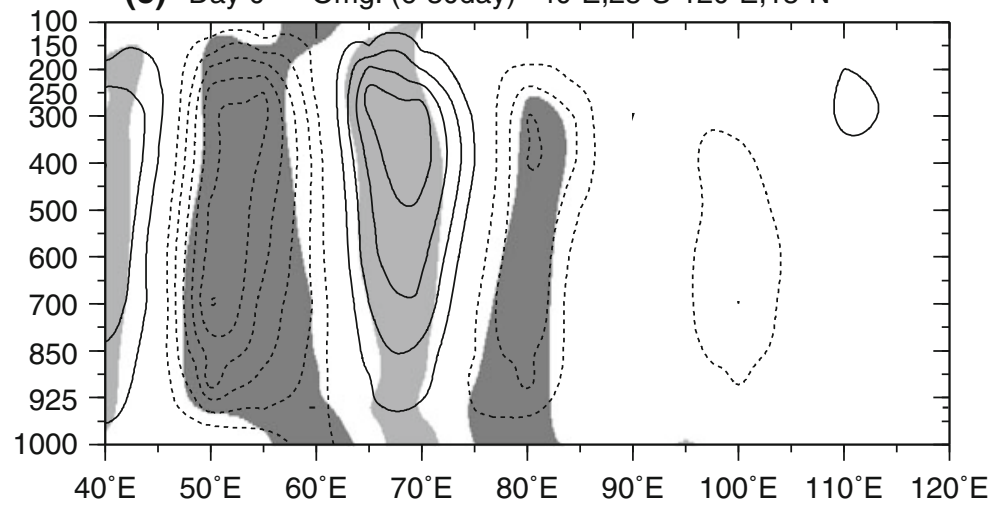

(d) Day $0 \quad \mathrm{~T}\left(6-30\right.$ day) $\quad 40^{\circ} \mathrm{E}, 25^{\circ} \mathrm{S}-120^{\circ} \mathrm{E}, 15^{\circ} \mathrm{N}$

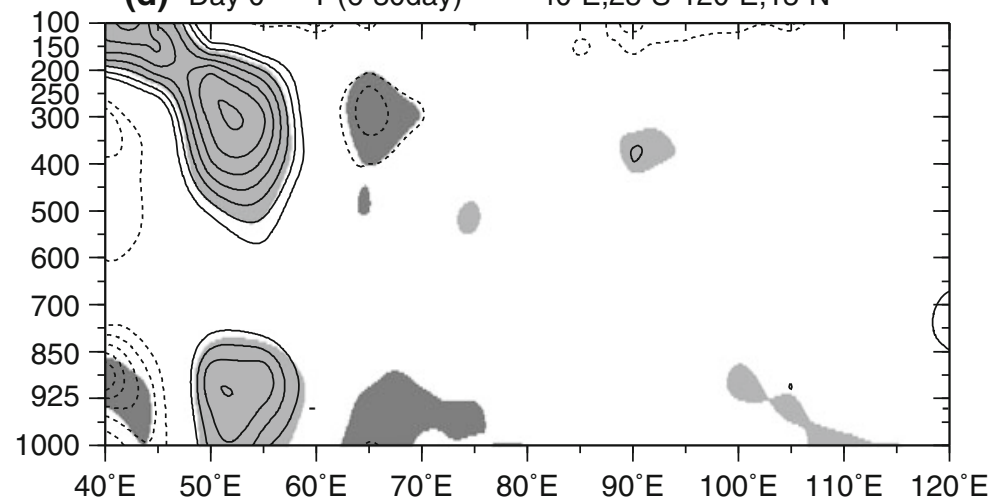




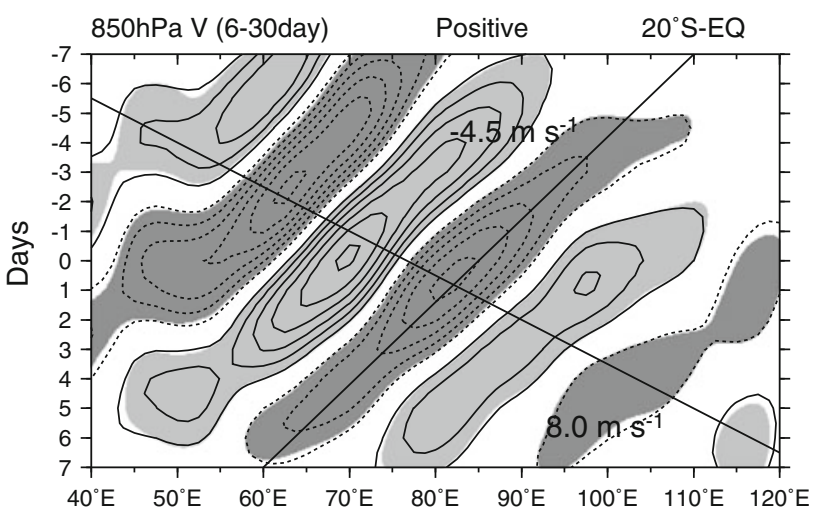

Fig. 8 Longitude-time cross section of 6-30-day filtered $850-\mathrm{hPa}$ meridional wind anomalies along the band of $20^{\circ} \mathrm{S}-\mathrm{EQ}$. Solid (dashed) contours indicate positive (negative) values. Contour interval is $0.3 \mathrm{~m} \mathrm{~s}^{-1}$. Positive (negative) anomalies with statistically significant at the $95 \%$ level are lightly (darkly) shaded. The thick solid linear lines indicate the approximate westward phase propagation and eastward group propagation

be about -4 to $-5 \mathrm{~m} \mathrm{~s}^{-1}$ and $7-9 \mathrm{~m} \mathrm{~s}^{-1}$, respectively, in these diagrams.

We apply lag-correlation statistics to the submonthlyfiltered fields to reveal climatological characteristics of the wave disturbances, following the method used by Lau and Lau (1990). They employed one-point lag-correlation techniques devised by Wallace et al. (1988) to estimate several measures of tropical wave disturbance characteristics: phase propagation vectors, temporal coherence, and the growth/decay rates of tropical synoptic-scale disturbances. We also calculate these three quantities based on lag-correlation analyses at each grid point. Figure 9 displays the resulting geographical distribution of phase propagation vectors and the temporal coherence and growth/decay rates. These were derived from the one-point lagged correlation maps for the submonthly-filtered $850-\mathrm{hPa}$ meridional wind anomalies for the winters of 1979/1980 through 2007/2008.

Phase propagation vectors and temporal coherence (Fig. 9a) are calculated by the positive extremes of the lagged correlation coefficients closest to a particular base point at day 0 . The orientation of a propagation vector is determined by the movement direction of the positive extreme from day -3 to day +3 . The magnitude of the vector indicates the phase propagation speed estimated from the displacement distance of the positive extreme during the 6-day interval. The temporal coherence, which is an indicator of the maintenance of migratory signals, is defined by the average of the positive correlation extremes on day -3 and day +3 . These quantities are assigned to the base point at day 0 . The propagation vectors are plotted only in the region with temporal coherence larger than 0.3. All vectors over the tropical Indian Ocean are directed westward and southwestward, supporting the wave propagation features shown in the previous section. A region of strong temporal coherence larger than 0.4 almost covers the strong teleconnectivity band (Fig. 1d) over the tropical Indian Ocean, highlighting a wave propagation characteristic of the submonthly-scale disturbances. In short, the waves identified in the composite fields (Figs. 4, 5, 6) are well characterized by this type of lag-correlation statistic. Here, we can see that strong temporal coherence is absent in the western Maritime Continent-South China Sea region. The region of strong temporal coherence over the tropical Indian Ocean terminates around $100^{\circ} \mathrm{E}$ and is discontinuous with strong signals over the tropical western Pacific. This implies that strong propagating disturbances originating over the tropical western Pacific tend to not directly affect the fluctuations over the tropical Indian Ocean.

The growth/decay rates of the disturbances are similarly derived from extremes of lagged correlation and regression coefficients at day -1 and day +1 (Fig. 9b), following the formula by Lau and Lau (1990). The most prominent feature is a large, strong growth region over the equatorial eastern Indian Ocean. This feature corresponds to the initial amplification of the equatorial gyres at the western end of the wave train just off northern Sumatra as seen in the composites (Figs. 4, 5, 6). Also, a strong decay region is located to the west of the growth region. The westward traveling disturbances could begin to decay in this region. Meanwhile, regions of comparatively weaker growth are scattered over the tropical Indian Ocean. These regions favor redevelopment of the disturbances, which could help organize the wave-train structure.

The strong degree of waviness and the coherent phase propagating nature of the submonthly-scale disturbances over the tropical Indian Ocean have been confirmed by examining lag-correlation statistics. The results support the spatiotemporal behavior of the prominent wave train identified in the composites. The strong temporal coherence of the waves and the band of high teleconnectivity (Fig. 1d) overlap the mean monsoon westerly flow (Fig. 1a), implying that the mean monsoon westerly flow acts as a tropical waveguide. The waveguide nature of the mean monsoon westerly flow can be identified by the axis of the maximum meridional gradient of absolute vorticity $\beta-\bar{U}_{y y}$, where $\bar{U}$ is the mean zonal wind, $\beta$ is the meridional gradient of planetary vorticity, and $-\bar{U}_{y y}$ is the approximated meridional gradient of relative vorticity. This quantity can be a good indicator for identifying an approximate location of a potential waveguide for Rossby waves in the midlatitude westerly region (e.g., Hsu and Lin 1992). We applied this to the tropical westerly region. Figure 10 illustrates the mean zonal wind and the meridional gradient of absolute vorticity for DJF from 1979/1980 to 2007/2008. A band of large values of $\beta-\bar{U}_{y y}$ extending 
Fig. 9 a Phase propagation vectors and temporal coherence for 6-30-day filtered $850-\mathrm{hPa}$ meridional wind field. Contour interval is 0.05 . The vectors and contours are plotted for the temporal coherence values are greater than 0.3. b Growth/ decay rates for the same field. Contour interval is $0.25 \mathrm{~m} \mathrm{~s}^{-1}$ day $^{-1}$. Solid (dashed) contours indicate positive (negative) values. Zero contours are omitted (a) Temporal Coherence \& Phase Propagation DJF 1979/80-2007/08

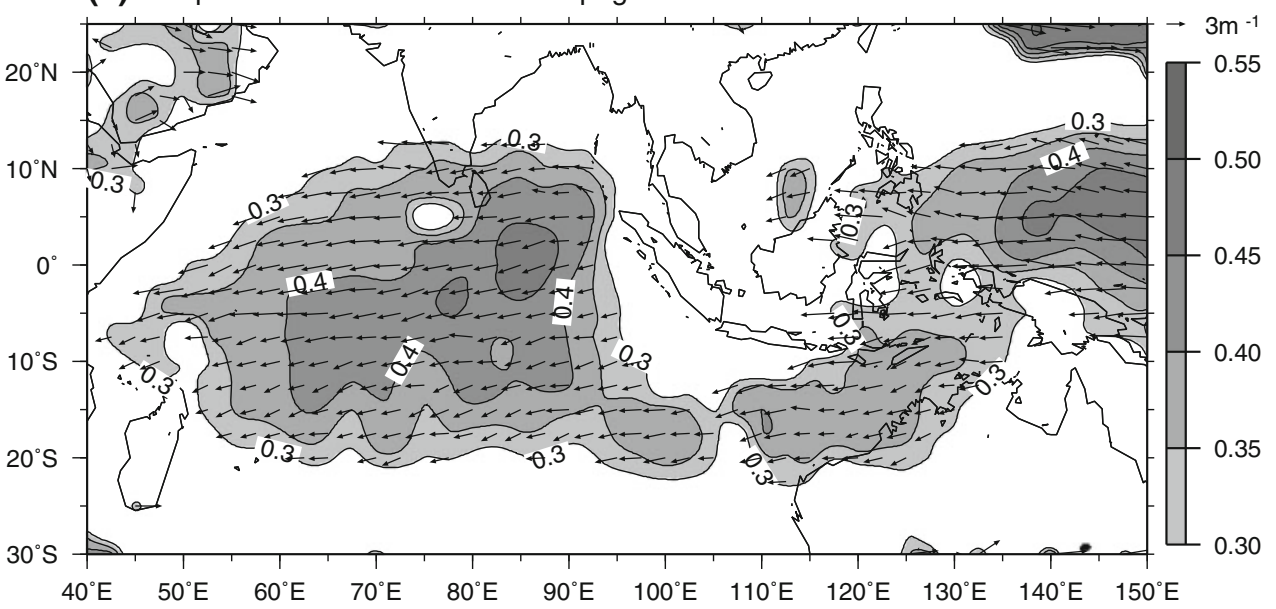

(b) Growth Rate $\left(\mathrm{m} \mathrm{s}^{-1}\right.$ day $\left.^{-1}\right)$

DJF 1979/80-2007/08

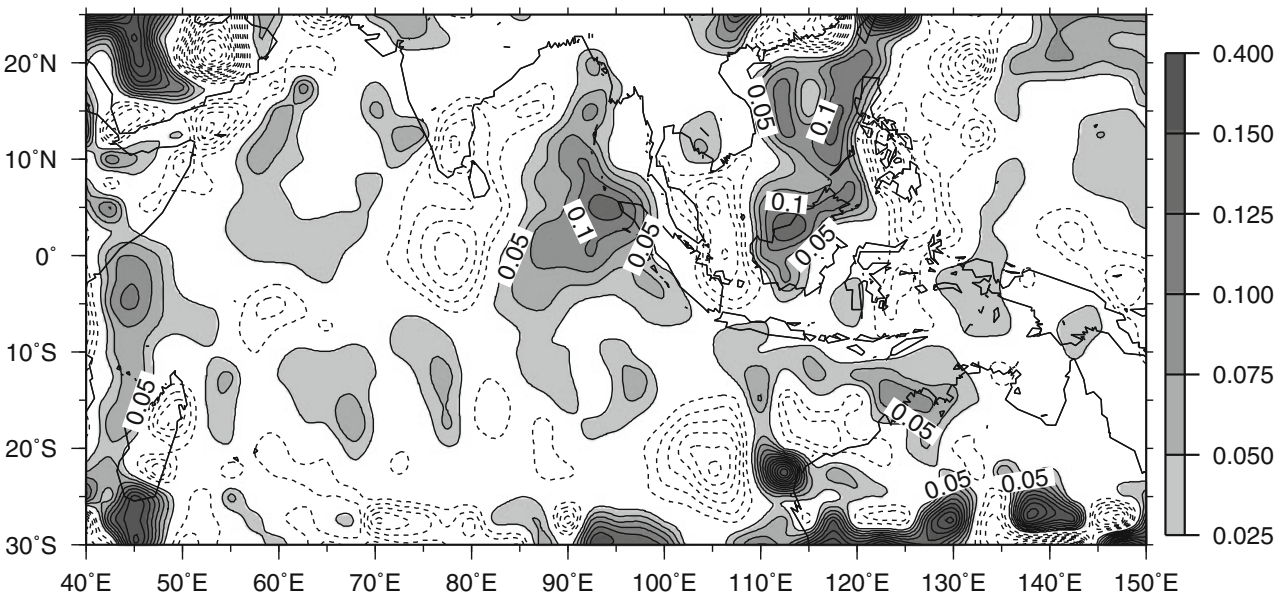

across the tropical Indian Ocean (Fig. 10b) is collocated with the mean westerly flow (Fig. 10a). Comparison of Figs. 1d and $10 \mathrm{a}, \mathrm{b}$ and indicates that the strong wave activity can be associated with these mean background states. The composite waves (Figs. 4, 5, 6) clearly tend to propagate through the band of $\beta-\bar{U}_{y y}$. In terms of barotropic vorticity dynamics, the large meridional gradient of absolute vorticity can help maintain the vorticity waves (as in Fig. 6) through the absolute vorticity advection effect. Hence, the band of $\beta-\bar{U}_{y y}$ yielded by the distribution of $\bar{U}$ could provide favorable background conditions for the propagation and maintenance of the wave disturbances. The westward and southwestward propagating waves in the composites appear to be trapped in the large $\beta-\bar{U}_{y y}$ region over the tropical Indian Ocean.

\section{January 2001 case study}

This section presents a typical case of submonthly-scale waves propagating over the tropical Indian Ocean. The wave-propagation episode selected for the case study occurred during early to mid-January 2001. This episode well represents the features identified in the composite results. Figure 11 illustrates the development of the 6-30day filtered $850-\mathrm{hPa}$ meridional wind and wind vector anomalies spanning from 2 to 9 January. This period covers one cycle of the oscillation, which includes one positive peak phase (2 January) and one negative peak phase (7 January) of the index for the composites.

An anomalous trough-ridge couplet with southwestnortheast orientation is developing over the southwestern Indian Ocean on 2 January (Fig. 11a). At this time, circulation signals are rather weak and the wave-train pattern is not clear over the eastern Indian Ocean. By 3 days later (Fig. 11b), a wave train extending across the tropical Indian Ocean has become established. This wave train pattern is similar to that seen in the composites. On 7 January (Fig. 11c), the wave train further amplifies toward the eastern Indian Ocean, suggesting that eastward and northeastward wave-energy dispersion occurs, as explained by the composite results. This may result in strengthening of an 
Fig. 10 a 29-SH summer climatology of 850-hPa zonal wind. Contour interval is $1.0 \mathrm{~m} \mathrm{~s}^{-1}$. Solid (dashed) contours indicate positive (negative) values. (b) Same as (a) except for meridional gradient of absolute vorticity. Contour interval is $2.0 \times 10^{-5} \mathrm{~s}^{-1}$
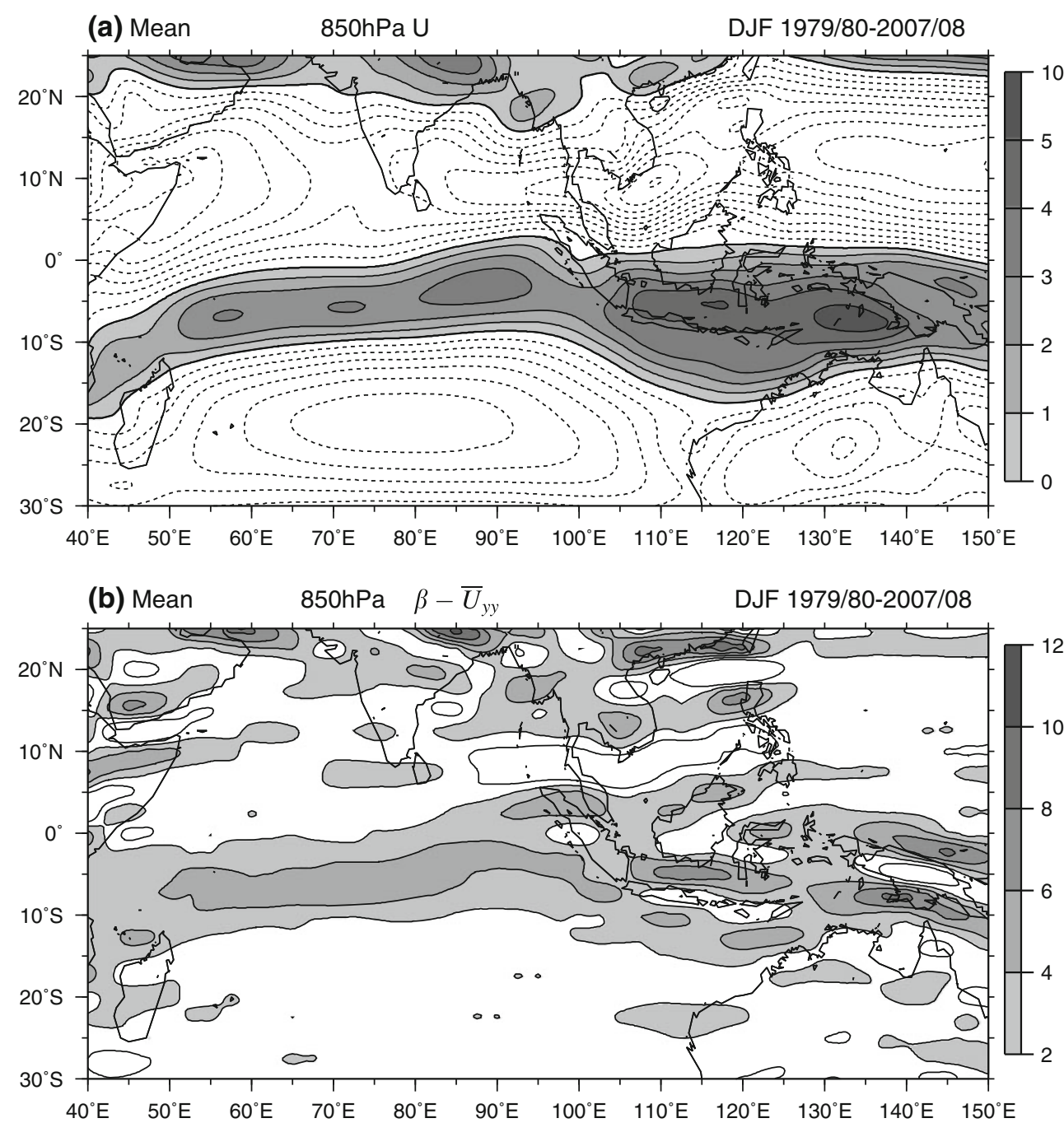

anticyclonic (counterclockwise) gyre in the eastern part of the wave train. On 9 January (Fig. 11d), the wave train slightly weakens but still maintains two well-developed cyclonic (clockwise) gyres. One is located at about $52^{\circ} \mathrm{E}, 28^{\circ} \mathrm{S}$ just to the southeast of Madagascar, and another is centered near $75^{\circ} \mathrm{E}, 15^{\circ} \mathrm{S}$ over the tropical central Indian Ocean. Entire patterns of the circulation anomalies shown in this case have many similarities to those in the composite results. The wave train develops eastward and northeastward with the amplification of troughs and ridges over the eastern Indian Ocean. The wave train is southwest-northeast-oriented, and anomalous troughs and ridges constituting the wave train continue to move westward and southwestward into the southwestern Indian Ocean throughout the sequence.

A sequence of total meridional component of winds, vector winds at $850 \mathrm{hPa}$, and OLR less than $220 \mathrm{~W} \mathrm{~m}^{-2}$ is also shown in Fig. 12 to confirm that the waves identified in the anomaly maps (Fig. 11) are reflected in the total flow fields. A wavy structure of the tropical flows that accompanies the ITCZ convective signal is evident. In addition, raw meridional wind patterns exhibit a wave-train-like structure resembling the anomalous meridional wind patterns (Fig. 11). Enhanced convective signals with lower OLR values tend to be associated with cyclonic flow regions. Through the sequence, cyclonic gyres over the tropical Indian Ocean are consistent with those in the wave train observed in the anomaly maps (Fig. 11). One can trace their westward and southwestward movement, as in the anomaly maps, from 2 to 9 January. These cyclonic gyres involve cores of deep convective signals indicated by OLR values below $200 \mathrm{~W} \mathrm{~m}^{-2}$, which suggests that they have convectively coupled wave characteristics along the Indian Ocean ITCZ. Consequently, the submonthly-scale waves identified in the anomaly maps play a role in modulating the ITCZ convective activity.

\section{Summary and discussion}

This study has examined the structure and characteristics of the wave disturbances on submonthly timescales over the 
Fig. 11 6-30-day filtered 850-hPa meridional wind (contours) and wind vector anomalies for a 2 , b 5, c 7, d 9 January 2001. Solid (dashed) contours indicate positive (negative) values. Contour interval is $2.0 \mathrm{~m} \mathrm{~s}^{-1}$ day $^{-1}$

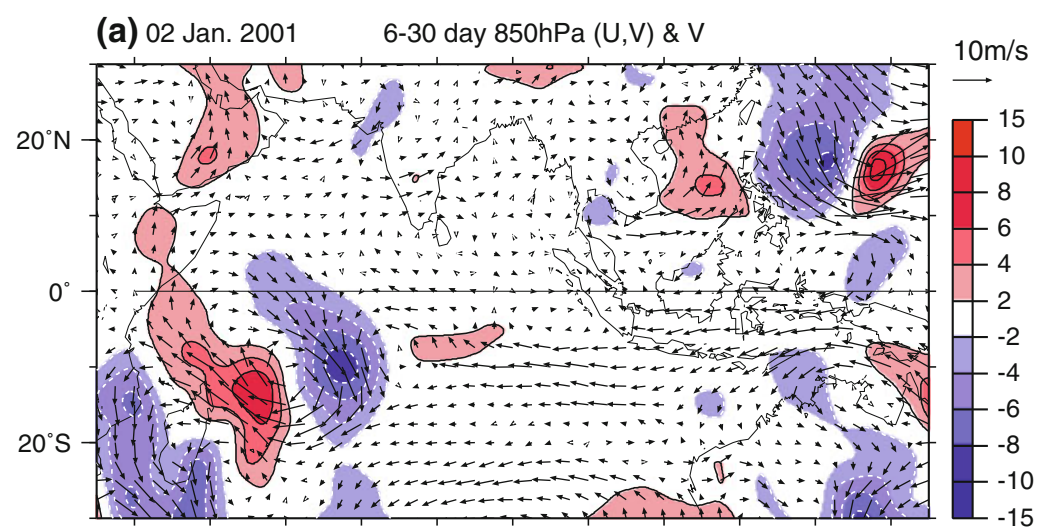

(b) 05 Jan. 2001

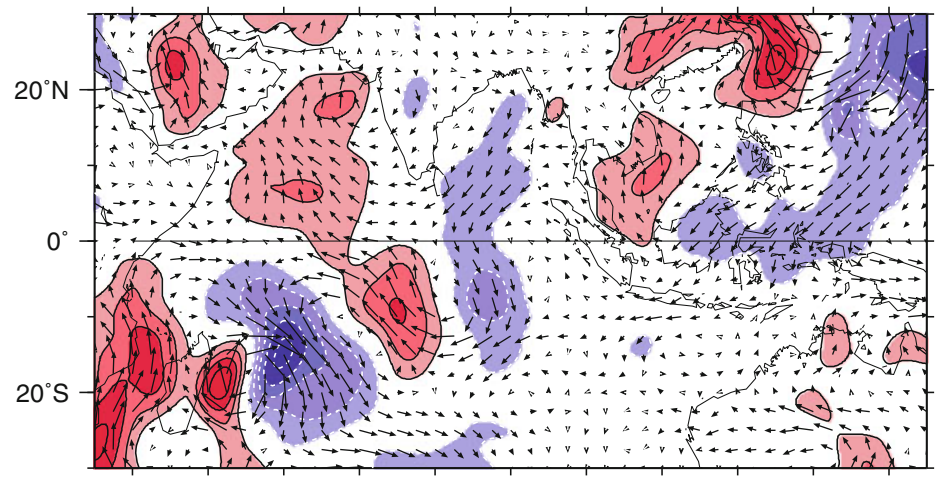

(c) 07 Jan. 2001

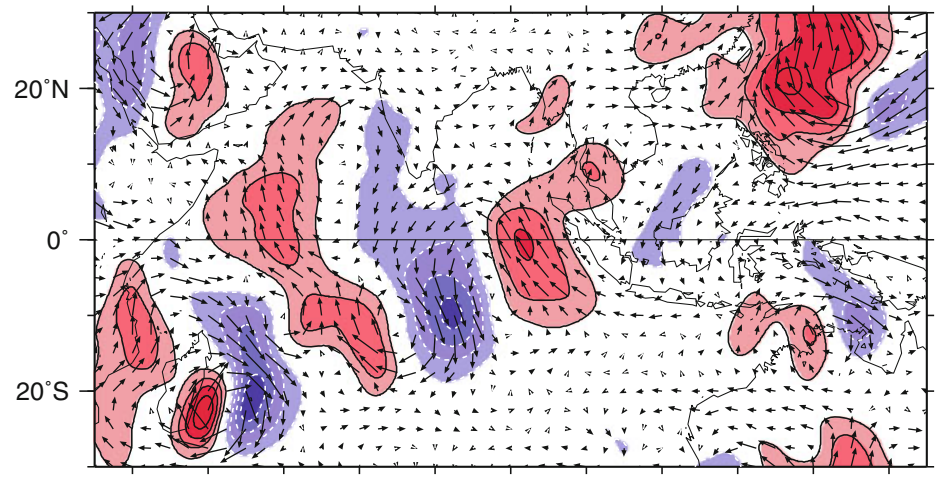

(d) 09 Jan. 2001

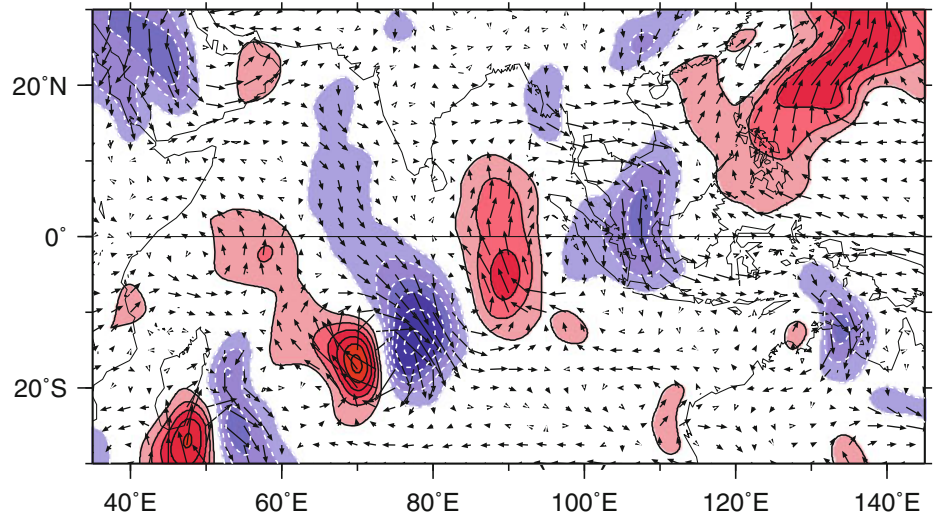


Fig. 12 Same as Fig. 11 except for total $850-\mathrm{hPa}$ meridional wind, wind vectors and OLR values less than $220 \mathrm{~W} \mathrm{~m} \mathrm{~s}^{-2}$. Contour interval is $2.0 \mathrm{~m} \mathrm{~s}^{-1} \mathrm{day}^{-1}$

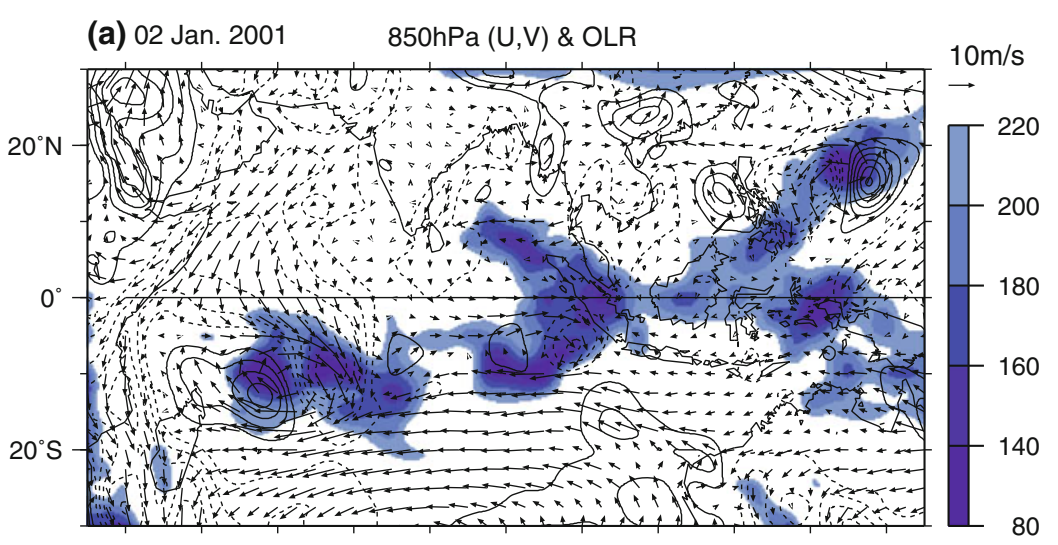

(b) 05 Jan. 2001

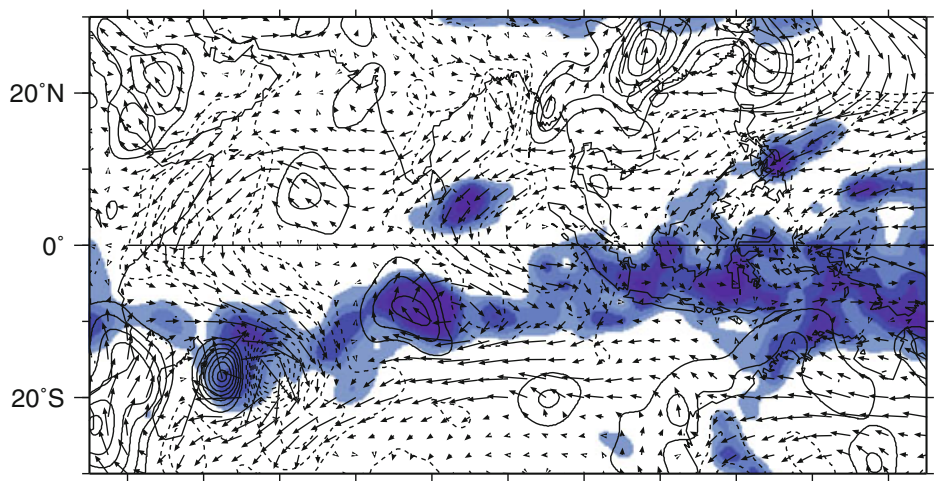

(c) 07 Jan. 2001

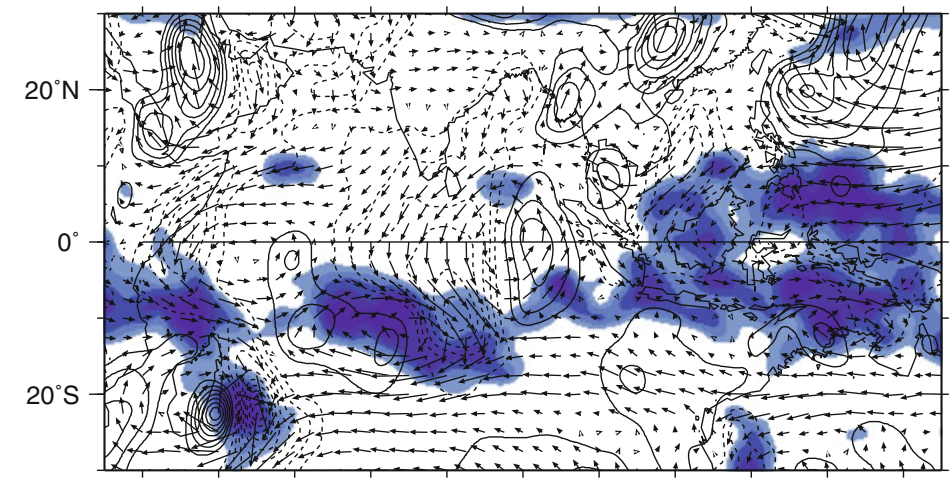

(d) 09 Jan. 2001

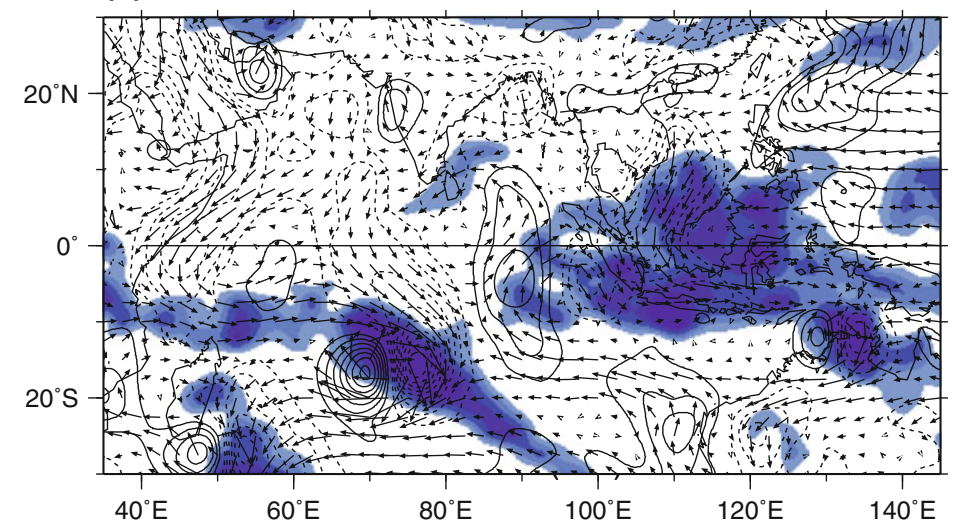


tropical Indian Ocean. The dominant modes of submonthly-scale variability have been detected by the EEOF analysis of the 850-hPa meridional wind anomalies. The pair of two modes (EEOFs 2 and 3) exhibits a wave-train pattern extending across the tropical Indian Ocean. The composite analysis based on the EEOF analysis result reveals the spatiotemporal structure and evolution of the wave train. The southwest-northeast-oriented wave train exhibits westward and southwestward phase propagation. The meridionally elongated troughs and ridges within the wave train move westward and southwestward from the west of Sumatra into Madagascar. Eastward and northeastward amplification of the waves clearly occurs in association with successive growth of new equatorial clockwise and counterclockwise gyres (troughs and ridges in the $\mathrm{SH}$ ) over the eastern Indian Ocean. This could be induced by wave-energy dispersion from the southwestern toward eastern Indian Ocean. Furthermore, the waves have convectively coupled wave characteristics and play a vital role in modulating the Indian Ocean ITCZ convection, which is supported by the troughs (ridges) within the wave train tending to accompany the enhanced (suppressed) convection signal in the ITCZ region.

The correlation statistics show the average behavior of the wave disturbances over the Indian Ocean. The teleconnectivity and temporal coherence of the $850-\mathrm{hPa}$ meridional winds, which are a good measure of propagating wave activity, determine the waveguide along the mean monsoon westerly flow over the tropical Indian Ocean. Moreover, the monsoon westerly flow is collocated with the band of large meridional gradient of absolute vorticity. These features suggest that the background condition produced by the monsoon westerly flow favors wave propagation across the tropical Indian Ocean. The propagation path of the waves identified in the composites almost corresponds to the axis of the band of strong teleconnectivity, highlighting that the mean monsoon westerly flow region acts as a tropical waveguide.

The case study of the wave-propagation episode in early January 2001 shows eastward and northeastward evolution of the wave train with westward and southwestward phase propagation. The features in this case are similar to those in the composite results. The wave signals identified in the anomaly fields well reflect those in the total fields. Cyclonic gyres as part of the wave train couple with deep convection along the Indian Ocean ITCZ.

In general, tropical rotational-type modes on the submonthly scales have been recognized as so-called equatorial Rossby (ER) waves. The horizontal structure of the waves during southern summer (boreal winter) identified in this study is different from that shown by previous studies that analyzed the waves in other seasons. Shinoda and Han (2005) and Wen et al. (2010) reported that the submonthly- scale waves exhibited a north-south double Rossby gyre structure symmetric about the equator in boreal autumn and spring, respectively. Chatterjee and Goswami (2004), Yokoi and Satomura (2006), and Fukutomi and Yasunari (2005, 2009) detected a north-south gyre Rossby pattern that shifted northward approximately $5^{\circ}-10^{\circ}$ from the equator. In the present results, a north-south pattern as shown in the above studies is not dominant, whereas a southwest-northeast-oriented wave-train pattern is pronounced. The circulation pattern represented by EEOF 4 (data not shown) may be associated with an almost zonally directed wave-train pattern localized in the equatorial eastern Indian Ocean. The seasonality of the submonthlyscale waves observed by the present and previous results could depend on structural differences of the mean flow in each season.

The southwest-northeast-oriented wave train identified in the present composites seems to be a mixture of distorted ER gyres and a mixed Rossby-gravity (MRG) wavelike gyre. Local maxima of anomalous zonal wind at the northern flank of the clockwise and counterclockwise gyres of the wave train tend to be located near the equator in the region west of about $80^{\circ}$. This feature is similar to that of an $\mathrm{n}=1 \mathrm{ER}$ wave. In contrast, the pattern of the equatorial gyres over the eastern Indian Ocean is nearly asymmetric about the equator and resembles an $n=0$ MRG wave. As the gyre moves westward, its center moves southward away from the equator. This movement off the equator of the equatorial gyres is analogous to that associated with the northwestward transition from a MRG wave to a tropical depression-type disturbance, as identified over the western North Pacific (e.g., Dickinson and Molinari 2002; Frank and Roundy 2006; Zhou and Wang 2007; Cheng and Huang 2009). Chen and Huang (2009) proposed that the northwestward transformation from a MRG mode into a Rossby mode is responsible for this transition. Possible physical mechanisms for this type of wave transition have been discussed in several of the above studies (e.g., Zhou and Wang 2007; Cheng and Huang 2009). However, it may be difficult to regard the equatorial gyre over the eastern Indian Ocean as a MRG-type wave. Because the predominant oscillating signal associated with the disturbances analyzed in this study substantially lies in the period longer than about 8-9 days as in the power spectra (Fig. 2). This timescale is longer than typical timescales for MRG waves that fall within the 3-6-day and 6-10-day ranges (e.g. Dickinson and Molinari 2002). Despite the fact that the timescale of the analyzed waves overlaps that of the lowerfrequency MRG waves near a 10-day period, it is still unclear whether the interpretation based on the MRG-wave dynamics is appropriate or not. Another possible interpretation is that the equatorial gyre is a kind of ER waves modified from their theoretical forms as discussed by 
Fukutomi and Yasunari (2009). The mechanism applicable to the present case still remains unclear. Further study is required to ascertain the cause of the wave transition over the tropical Indian Ocean. One of the plausible dynamic processes for the southward movement of the gyres of the wave train off the equator might be advection of the wave transients by the background mean flow. As illustrated in Fig. 1, the northerly winter monsoon flow extends from the Arabian Sea and Bay of Bengal into the SH-side equatorial region. When the vorticity budget (data not shown) for the composite vorticity waves (Fig. 6) is considered, advection of the transient eddy vorticity by the northerly mean flow seems to be an important factor for the southward migration of the waves.

The origin and initiation mechanism of the tropical wave train in this ITCZ region remain uncertain. Extratropical forcing could be a possible mechanism for the initial development of the tropical wave train. Tropicalextratropical interactions linking southern Africa to the midlatitudes of the southwest Indian Ocean, which occur in very close proximity to the present analysis region, have been shown by previous studies (e.g., Fauchereau et al. 2009; Manhique et al. 2009; Pohl et al. 2009; Cretat et al. 2010 ; Hart et al. 2010; Vigaud et al. 2012). Among these studies, Fauchereau et al. (2009), Cretat et al. (2010), and Hart et al. (2010) demonstrated that the northeastward propagation of midlatitude waves from the Atlantic toward the southwest Indian Ocean caused the development of tropical-temperate troughs, which were heavy rainfallproducing systems over southern Africa. As a natural extension of our study, we are interested in the role of such extratropical wave propagation in forcing the disturbance activity in the Indian Ocean ITCZ. We plan further work to investigate aspects of tropical-extratropical interactions associated with the development of the Indian Ocean ITCZ wave disturbances.

Acknowledgements We appreciate the comments of anonymous reviewers, which helped to improve an earlier version of the paper.

Open Access This article is distributed under the terms of the Creative Commons Attribution License which permits any use, distribution, and reproduction in any medium, provided the original author(s) and the source are credited.

\section{Appendix: Measures for wave disturbance activity based on the correlation statistics}

\section{Teleconnectivity}

The teleconnectivity at any grid point in a given domain is defined by the absolute value of the strongest negative correlation appearing on the one-point correlation map for that grid point (Wallace and Gutzler 1981; Wallace et al. 1988; Lau and Lau 1990). The teleconnectivity $T_{i}$ is generally written as

$T_{i}=\mid\left(R_{i j}\right.$ minimum for all $\left.j\right) \mid$.

where $R_{i j}$ is the simultaneous correlation between the base point $i$ and every point $j . T_{i}$ for all the one-point correlation maps is finally plotted on a single map. The $T_{i}$ map represents the extent to which the disturbances are wavelike. The large $T_{i}$ value indicates that fluctuations at the point $i$ is accompanied by strong fluctuations of the opposite polarity at other locations.

Phase propagation vectors and temporal coherence

The phase propagation vectors and temporal coherence for the band-pass filtered meridional wind anomalies are estimated based on lag-correlation maps following the method described in detail by Wallace et al. (1988) and Lau and Lau (1990). These quantities are computed as follows. We first prepared lag-correlation maps for lags of -3 and +3 day. We then identified the strongest positive correlation centers appearing in the maps for lags of -3 and +3 day. The phase propagation vectors are estimated by tracking these centers that pass the base point at lag 0 day while they travel from the location at lag -3 day to that at lag +3 day. Phase propagation speed of the disturbances is estimated by dividing the traveling distance of the centers by the total lags (i.e. 6 days). Finally, the phase propagation speed and direction are represented in vectorial format at each grid point. The length of the vectors gives the phase speed. The temporal coherence is defined as the average magnitude of a pair of the strongest positive lag-correlation center values at lags of -3 and +3 day. This quantity indicates that how well a disturbance is maintained during its traveling time.

\section{Growth/decay rates}

The growth/decay rates of the disturbances are estimated using a method analogous to that for the phase propagation vectors and temporal coherence. We tracked strongest positive correlation centers appearing in lag-correlation maps for lags of -1 and +1 day. These centers pass over the base point at lag 0 day during the 2-day interval from lag -1 day through lag +1 day. We then computed lagregression coefficients on the location of these centers at lags of -1 and +1 day following the formula defined by Lau and Lau (1990). These regression coefficients provide a measure of amplitude of the disturbances at these timings. The growth/decay rates were estimated by dividing the difference between these two regression coefficients by 
2 days. They provide a measure of amplification and decay of the disturbances during their travel from the lag -1 day through the lag +1 day.

\section{References}

Chatterjee P, Goswami BN (2004) Structure, genesis and scale selection of the tropical quasi-biweekly mode. Quart J R Meteor Soc 130:1171-1194

Chen G, Huang R (2009) Interannual variations in mixed Rossbygravity waves and their impacts on tropical cyclogenesis over the western North Pacific. J Clim 22:535-549

Cretat J, Richard Y, Pohl B, Rouault M, Reason CJC, Fauchereau N (2009) Recurrent daily rainfall patterns over South Africa and associated dynamics during the core of the austral summer. Int J Climatol. doi:10.1002/joc.2266

de Laat AT (2002) Interannual variability of the Indian winter monsoon circulation and consequences for pollution levels. J Geophys Res D 24:4739. doi:10.1029/2001JD001483

Dickinson M, Molinari J (2002) Mixed Rossby-gravity waves and western Pacific tropical cyclogenesis. Part I: Synoptic evolution. J Atmos Sci 59:2183-2196

Duncan B, Han W (2009) Indian Ocean intraseasonal sea surface temperature variability during boreal summer: Madden-Julian Oscillation versus submonthly forcing and processes. J Geophys Res 114:C05002. doi:10.1029/2008JC004958

Fauchereau N, Pohl B, Reason CJC, Rouault M, Richard Y (2009) Recurrent daily OLR patterns in the Southern Africa/Southwest Indian Ocean region, implications for South African rainfall and teleconnections. Clim Dyn 32:575-591

Frank WM, Roundy PE (2006) The role of tropical waves in tropical cyclogenesis. Mon Wea Rev 134:2397-2417

Fukutomi Y, Yasunari T (2002) Tropical-extratropical interaction associated with the 10-25-day oscillation over the western Pacific during the northern summer. J Meteor Soc Japan 80:311-331

Fukutomi Y, Yasunari T (2005) Southerly surges on submonthly time scales over the eastern Indian Ocean during the Southern Hemisphere winter. Mon Wea Rev 133:1637-1654

Fukutomi Y, Yasunari T (2009) Cross-equatorial influences of submonthly scale southerly surges over the eastern Indian Ocean during the Southern Hemisphere winter. J Geophys Res 133:1637-1654

Han W, Liu WT, Lin J (2006) Impact of atmospheric submonthly oscillations on sea surface temperature of the tropical Indian Ocean. Geophys Res Lett 33:L03609. doi:10.1029/2005GL25082

Han W, Yuan D, Liu WT, Halkides DJ (2007) Intraseasonal variability of Indian Ocean intraseasonal sea surface temperature during boreal winter: Madden-Julian Oscillation versus submonthly forcing and processes. J Geophys Res 112:C04001. doi: 10.1029/2006JC003791

Hart NCG, Reason CJC, Fauchereau N (2010) Tropical-extratropical interactions over Southern Africa: Three cases of heavy summer season rainfall. Mon Wea Rev 138:2608-2623

Hsu H-H, Lin S-H (1992) Global teleconnections in the 250-mb streamfunction field during the northern hemisphere winter. Mon Wea Rev 120:1169-1190

Jury MR, Pathack B, Campbell G, Wang B, Landman W (1991) Transient convective waves in the tropical SW Indian Ocean. Meteor Atmos Phys 47:27-36

Jury MR, Pathack B (1991) A study of weather and climate variability over the tropical Southwest Indian Ocean. Meteor Atmos Phys $47: 37-48$
Kaylor RE (1977) Filtering and decimation of digital time series. Tech Note BN 850, Institute of Physical Science Technology, University of Maryland, $\mathrm{p} 42$

Kiladis GN, Weickmann KM (1992) Circulation anomalies associated with tropical convection during northern winter. Mon Wea Rey 120:1900-1923

Kiladis GN, Meehl GA, Weickmann KM (1994) Large-scale circulation associated with westerly wind bursts and deep convection over the western equatorial Pacific. J Geophys Res 99:1852718544

Kiladis GN, Wheeler M (1995) Horizontal and vertical structure of observed tropospheric equatorial waves. J Geophys Res 100: 22281-22997

Kiladis GN, Weickmann KM (1997) Horizontal structure and seasonality of large-scale circulations associated with submonthly tropical convection. Mon Wea Rev 125:1997-2013

Krishnamurti TN, Jha B, Rasch PJ, Ramanathan V (1997) A high resolution global reanalysis highlighting the winter monsoon. Part II: Transients and passive tracer transports. Meteor Atmos Phys 64:151-171

Krishnamurti TN, Chakraborty A, Martin A, Lau WK, Kim K-M, Sud Y, Walker G (2009) Impact of Arabian Sea pollution on the Bay of Bengal winter monsoon rains. J Geophys Res 114:D06213. doi:10.1029/2008JD010679

Lau K-H, Lau N-C (1990) Observed structure and propagation characteristics of tropical summertime synoptic scale disturbances. Mon Wea Rev 118:1888-1913

Lelieveld J, coauthors (2001) The Indian Ocean Experiment: Widespread air pollution from South and Southeast Asia. Science 291:1031-1036

Maloney ED, Dickinson MJ (2003) The intraseasonal oscillation and the energetics of summertime tropical western north Pacific synoptic-scale disturbances. J Atmos Sci 60:2153-2168

Manhique AJ, Reason CJC, Rydberg L, Fauchereau N (2009) ENSO and Indian Ocean sea surface temperatures and their relationships with tropical temperate troughs over Mozambique and the Southwest Indian Ocean. Int J Climatol doi:10.1002/joc.2050

Masumoto Y, Hase H, Kuroda Y, Matsuura H, Takeuchi K (2005) Intraseasonal variability in the upper layer currents observed in the eastern equatorial Indian Ocean. Geophys Res Lett 32:L02607. doi:10.1029/2004GL021896

Masumoto Y, Horii T, Ueki I, Hase H, Ando K, Mizuno K (2008) Short-term upper-ocean variability in the central equatorial Indian Ocean during 2006 Indian Ocean Dipole event. Geophys Res Lett 35:L14S09. doi:10.1029/2008GL033834

Meehl GA, Kiladis GN, Weickmann KM, Wheeler M, Gutzler DS, Compo GP (1996) Modulation of equatorial subseasonal convective episodes by tropical-extratropical interaction in the Indian and Pacific Ocean regions. J Geophys Res 101:15033-15049

Murakami T, Sumi A (1981) Large-scale aspects of the 1978-79 winter circulation over the greater WMONEX region. Part II: Long-period perturbations. J Meteor Soc Japan 59:646-671

Nassor A, Jury MR (1998) Intra-seasonal climate variability of Madagascar. Part 1: mean and summer conditions. Meteor Atmos Phys 65:31-41

Numaguti A (1995) Characteristics of 4-to-20 day period disturbances observed in the equatorial Pacific during the TOGACOARE IOP. J Meteor Soc Japan 73:353-377

Ogata T, Sasaki H, Murty VSN, Sarma MSS, Masumoto Y (2008) Intraseasonal meridional current variability in the eastern equatorial Indian Ocean. J Geophys Res 113:C07037. doi: 10.1029/2007JC00431

Onogi K, coauthors (2005) JRA-25; Japanese 25-year reanalysisprogress and status. Quart J R Meteor Soc 131:3259-3268

Onogi K, coauthors (2007) The JRA-25 analysis. J Meteor Soc Japan 85: 369-4 
Pires P, Redelsperger J-L, Lafore J-P (1997) Equatorial atmospheric waves and their association to convection. Mon Wea Rev 125:1167-1184

Pohl B, Fauchereau N, Richard Y, Rouault M, Reason CJC (2009) Interactions between synoptic, intraseasonal and interannual convective variability over Southern Africa. Clim Dyn 33:1033-1050

Ramanathan V, coauthors (2001) Indian ocean experiment: an integrated analysis of climate forcing and effects of the great Indo-Asian haze. J Geophys Res 106: 28371-28398

Roundy PE, Frank WM (2004) A climatology of waves in the equatorial region. J Atmos Sci 61:2105-2132

Schrage JM, Clayson CA, Strahl B (2001) Statistical properties of episodes of enhanced 2-3-day convection in the Indian and Pacific oceans. J Clim 14:3482-3494

Sengupta D, Senan R, Goswami BN (2001) Origin of intraseasonal variability of circulation in the tropical central Indian Ocean. Geophys Res Lett 28:1267-1270

Sengupta D, Senan R, Murty VSN, Fernando V (2004) A biweekly mode in the equatorial Indian Ocean. J Geophys Res 109:C1003. doi: 10.10129/2004JC00239

Shinoda T, Han W (2005) Influence of the Indian Ocean Dipole on atmospheric subseasonal variability. J Clim 18:3891-3909

Tomas RA, Webster PJ (1997) On the location of the intertropical convergence zone and near-equatorial convection: The role of inertial instability. Quart J R Meteor Soc 123:1445-1482

Vera CS, Vigliarolo PK, Berbery EH (2002) Cold season synopticscale waves over subtropical South America. Mon Wea Rev 130:684-699

Verver GHL, Sikka DR, Lobert JM, Stossmeister G, Zachariasse M (2001) Overview of the meteorological conditions and atmospheric transport processes during INDOEX 1999. J Geophys Res 106:28399-28413

Vigaud N, Pohl B, Cretat J (2012) Tropical-temperate interactions over southern Africa simulated by a regional climate model. Clim Dyn. doi:10.1007/s00382-012-1214-3

Vincent DG, Fink A, Schrage JM, Speth P (1998) High- and lowfrequency intraseasonal variance of OLR on annual and ENSO timescales. J Clim 11:968-986

Waliser DE, Gautier C (1993) A satellite-derived climatology of the ITCZ. J Clim 4:2162-2174

Wallace JM, Gutzler DS (1981) Teleconnections in the geopotential height field during the northern hemisphere winter. Mon Wea Rev 109:784-812

Wallace JM, Lim G-H, Blackmon ML (1988) Relationship between cyclone tracks, anticyclone tracks, and baloclinic waveguides. J Atmos Sci 45:439-462

Wen M, Li T, Zhang R, Qi Y (2010) Structure and origin of the quasibiweekly oscillation over the Tropical Indian Ocean in boreal spring. J Atmos Sci 67:1965-1982

Wheeler M, Kiladis GN (1999) Convectively coupled equatorial waves: Analysis of clouds and temperature in the wavenumverfrequency domain. J Atmos Sci 56:374-399

Yokoi S, Satomura T (2006) Mechanisms of the northward movement of submonthly scale vortices over the Bay of Bengal during the boreal summer. Mon Wea Rev 134:2265-2551

Zhou X, Wang B (2007) Transition from an eastern Pacific upper-level mixed Rossby-gravity wave to a western Pacific tropical cyclone. Geophys Res Lett 34:L24801. doi:10.1029/2007GL031831 